Revista de
Economild
Contemporâned

\title{
INFORMALIDADE E SEGMENTAÇÃO DO MERCADO DE TRABALHO BRASILEIRO NOS ANOS 2000: UMA DECOMPOSIÇÃO QUANTÍLICA DE DIFERENCIAIS DE RENDIMENTOS
}

\author{
Francieli Tonet Maciel $^{a}$ \\ Ana Maria Hermeto C. de Oliveira ${ }^{b}$
aProfessora Substituta do Departamento de Ciências Econômicas da Universidade Federal de Minas Gerais (FACE/UFMG).

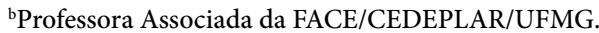

Artigo recebido em 19/01/2017 e aceito para publicação em 27/04/2018.

RESUMO: Este artigo decompõe as mudanças nos diferenciais de rendimentosentre trabalho formal e informalna última década no Brasil, entre efeitos de composição e de segmentação, separadamente por gênero. São utilizados os microdados dos Censos Demográficos de 2000 e 2010, e o método de Machado e Mata (2005) para a decomposição ao longo da distribuição de rendimentos, com correção de seleção amostral. Para mulheres e homens, verificou-se que o efeito de segmentação contribuiu para aumentar a vantagem de rendimentos para o trabalho formal na base da distribuição, enquanto que o efeito de composição contribuiu para reduzir esses diferenciais ao longo de toda a distribuição, sendo, no entanto, maior no topo do que na base da distribuição de rendimentos. Contudo, verificou-se diferenças importantes por gênero quanto ao nível e variação desses componentes no período e ao longo da distribuição. O nível de desigualdade é maior entre as mulheres do que entre os homens, sendo o efeito de segmentação ainda mais grave para o trabalho informal feminino na base da

Correspondência para: Francieli Tonet Maciel

Contato: francieli.tonet@gmail.com 
distribuição. Por outro lado, a redução no efeito de composição se mostrou superior entre as mulheres ao longo de toda a distribuição, acarretando em uma queda do diferencial total a partir do $30^{\circ}$ quantil maior para o trabalho feminino, ainda que este permaneça inferior para o trabalho masculino.

PALAVRAS-CHAVE: informalidade; diferenciais de rendimentos; decomposição; regressão quantílica; viés de seleção.

CLASSIFICAÇÃO JEL: J31; J46. 


\title{
INFORMALITY AND SEGMENTATION OF THE BRAZILIAN LABOR MARKET IN THE 2000s: A QUANTILE DECOMPOSITION OF EARNINGS DIFFERENTIALS
}

\begin{abstract}
This paper decomposes the changes in the earnings differentials between formal and informal labor over the last decade in Brazil, between composition and segmentation effects, separately by gender. We use microdata from the Demographic Census of 2000 and 2010 and follow Machado and Mata's (2010) method to decompose the changes along the earnings distribution with correction for sample selection. For women and men, the segmentation effect contributed to increase the earnings advantage to formal labor at the bottom of the earnings distribution, while the composition effect contributed by decreasing these differentials along the earnings distribution, but this effect is higher at the top than the bottom of the distribution. However, there are important differences by gender in the level and variation of these components over the period and along the earnings distribution. Inequality level is higher among women than among men, and the segmentation effect is more severe for female informal labor at the bottom of the distribution. On the other hand, the reduction in the composition effect along the earnings distribution was higher among women than among men, resulting in a decrease of the total differential, from the 30th quantil, higher for the female labor, although this differential remains lower for the male labor.
\end{abstract}

KEYWORDS: informality; earnings differentials; decomposition; quantile regression; selection bias. 


\section{INTRODUÇÃO}

A literatura a respeito da dinâmica da informalidade do mercado de trabalho é vasta e abrange uma diversidade de abordagens teóricas e conceituais em razão da complexidade das relações estabelecidas entre economia formal e informal. Embora a informalidade constitua um fenômeno estruturalmente característico de economias emergentes e em desenvolvimento, ela também ganha importância global em diferentes contextos, mesmo nas economias com mercados de trabalho estruturados, dado o processo de desenvolvimento do capitalismo, renovando o interesse e fomentando um debate contínuo sobre o tema.

No âmbito da teoria econômica, a literatura relativa à informalidade remete à teoria do mercado de trabalho dual (DOERINGER e PIORE, 1971; PIORE, 1972; REICH, GORDON e EDWARDS, 1973; VIETORISZ e HARRISON, 1973). Esta teoria é o ponto de partida dos estudos que consideram a hipótese de segmentação para explicar os diferenciais de salários entre os setores formal e informal da economia, sobretudo para a literatura no contexto dos países em desenvolvimento. Embora existam diferenciações acerca do que se entende por segmentação, a hipótese central é a de que existem retornos distintos ao capital humano, ou seja, os mecanismos de determinação dos salários variam segundo o segmento do mercado de trabalho, e de que há racionamento dos postos de trabalho no setor formal.

Contudo, a primeira aparição do termo "setor informal" em um documento oficial foi no relatório da missão global de emprego para o Quênia, realizado pela Organização Internacional do Trabalho (OIT) em 1972. Os estudos da OIT, combinados ao trabalho de Hart (1973), abriram espaço para a análise do setor informal através de distintas abordagens teóricas, gerando diferentes interpretações. Na América Latina, em especial, destacam-se as contribuições de Souza e Tokman (1976), Tokman (1977) e Souza (1980), segundo as quais o setor informal se origina como consequência do excedente da força de trabalho não ocupada pelo setor formal, bem como a abordagem de Gerry (1978) e Moser (1980) que se diferencia, basicamente, por partir da análise dos mecanismos históricos pelos quais a relação entre o setor formal e o informal se estabelece.

Nos anos 1980, em um contexto de crescente importância das atividades informais em diferentes conjunturas econômicas e sociais, destaca-se a contribuição de Portes, Castells e Benton (1989), que incide sobre a análise da redefinição das relações de produção através da articulação de atividades formais e informais, em razão de uma descentralização e da busca de maior flexibilidade da produção por meio da intensificação das relações de subcontratação, principalmente nos países desenvolvidos. Do ponto de vista da estratégia ocupacional, há ainda a abordagem que se refere à informalidade como “voluntária" (FIELDS, 1990; MALONEY, 1998). Esta se assemelha, em certa medida, à 
abordagem legalista (DE SOTO et al., 1986), ao considerar o custo de oportunidade de trabalhar informalmente, e que parte do setor informal seria, portanto, um reflexo da alocação eficiente do trabalho, refletindo uma escolha voluntária do trabalhador.

O crescente processo de precarização do trabalho levou à preocupação com o setor informal como uma erosão estrutural da capacidade de proteção e, portanto, de coesão social. Em 2002, a OIT ampliou o conceito de "setor informal" para "economia informal", que passou a abranger um grupo diversificado de trabalhadores e empresas, que operam informalmente. Eles diferem em termos do tipo de unidade de produção (abordagem da empresa) e do tipo de posição na ocupação (abordagem do trabalho), e têm como característica comum a falta de proteção legal, assim como a situação de vulnerabilidade no emprego e na renda.

Em que pese os avanços do conceito de economia informal à luz da OIT, especialmente quanto à percepção da dimensão do fenômeno, este se mostra muito mais complexo na medida em que sua crescente heterogeneidade e relações cada vez mais estreitas com as atividades formais nas últimas três décadas conformam para novas configurações e condições de trabalho. Cacciamali (2000) denomina esse processo de mudanças estruturais de "processo de informalidade". Na concepção da autora, no contexto da América Latina da década de 1990, esse processo deve ser associado às diferentes formas de inserção ocupacional, especialmente no que diz respeito à reformatação das relações e contratos de trabalho no setor formal da economia e ao "auto emprego", enfatizando a coexistência entre novas e velhas formas de ocupação informal. Particularmente no caso Brasil, a dinâmica econômica que se estabeleceu na década de 1990 configurou-se pelo aprofundamento da heterogeneidade da estrutura ocupacional.

Nesse sentido, partindo da abordagem das relações de trabalho, o presente estudo entende que o conceito de informalidade, em especial no que se refere ao mercado de trabalho brasileiro, compreende diferentes tipos de inserção do trabalho, não pelas semelhanças entre eles, mas pelo distanciamento que mantém das relações de assalariamento e contratos permanentes de trabalho, abrangendo, portanto, diferentes categorias de ocupação. Contudo, por constituírem formas distintas de inserção da força de trabalho, uma análise conjunta de tais categorias pode negligenciar suas particularidades. Tendo em vista que a análise aqui proposta parte da percepção da precariedade do trabalho, em que as relações são tipicamente definidas pela dinâmica capitalista, enfatiza-se particularmente as relações de trabalho que não estão sujeitas à legislação trabalhista vigente, ou seja, o emprego assalariado sem carteira de trabalho.

Em movimento contrário ao observado nos anos 1990, a última década foi marcada por um crescimento expressivo do emprego acompanhado por uma menor incidência do trabalho informal no Brasil. Conforme dados dos Censos Demográficos de 2000 e 2010, a taxa de participação do emprego assalariado sem carteira apresentou 
uma redução de $14 \%$, passando de $30 \%$ para $25,84 \%$ do total da ocupação. Essa queda está associada ao crescimento do emprego formal que respondeu por $82 \%$ do aumento da taxa de ocupação no período. Além disso, fatores como o aumento da participação feminina no mercado de trabalho, do grau de escolaridade e de alterações na estrutura etária da população, provocaram mudanças de perfil na força de trabalho.

Nesse contexto, emergem questões relacionadas ao papel dessas mudanças na demanda e oferta de trabalho sobre a desigualdade entre trabalho formal e informal na década de 2000, que refletem a necessidade de um reposicionamento da discussão acerca dessa dinâmica formal-informal no mercado de trabalho brasileiro. Teria ocorrido uma diminuição das diferenças quanto aos mecanismos de determinação dos rendimentos, ou seja, quanto à segmentação entre ocupação formal e informal? Haveria uma mudança na composição relativa entre os grupos suficiente para reduzir a desigualdade entre eles? Seria o peso desses fatores distinto e, portanto, os efeitos de suas mudanças divergentes entre os trabalhadores nos diferentes pontos da distribuição dos rendimentos? Seriam essas mudanças mais significativas para o trabalho feminino ou masculino?

Mudanças em fatores institucionais, como no poder de barganha dos sindicatos ou no salário mínimo, podem aumentar a segmentação no mercado de trabalho em razão de maiores retornos relativos ao emprego formal e, portanto, provocar um aumento da desigualdade entre trabalho formal e informal, no último caso principalmente entre os trabalhadores nos estratos de renda mais baixos. Por outro lado, argumenta-se que, se a valorização do salário mínimo tem efeito sobre os rendimentos dos trabalhadores informais, então haveria uma redução da desigualdade. Alterações de perfil da força de trabalho associadas ao aumento da escolaridade, por exemplo, reduz a desigualdade na medida que diminui a heterogeneidade entre os trabalhadores formais e informais, contudo, se estes forem mais heterogêneos nos estratos mais altos do que nos mais baixos, essa mudança de composição tem maior efeito sobre os trabalhadores no topo do que na base da distribuição dos rendimentos.

Nesse sentido, o objetivo do presente trabalho é analisar os efeitos das mudanças na composição relativa e na segmentação entre trabalho formal e informal, na década de 2000, sobre os diferenciais de rendimentos entre os grupos no Brasil. Para tanto, utiliza-se o método de decomposição de Machado e Mata (2005) que, a partir da estimação de regressões quantílicas, permite verificar quanto da variação na desigualdade é devida às mudanças nas características observáveis dos trabalhadores e quanto se deve às mudanças associadas aos retornos a essas características, ou seja, aos efeitos de composição e segmentação, ao longo de toda a distribuição de rendimentos. Além disso, considera-se fundamental a desagregação da análise por gênero, na medida que há diferenças quanto à participação feminina e masculina no mercado de trabalho. 
Dessa maneira, este estudo visa contribuir para o preenchimento de algumas lacunas na literatura nacional sobre o tema, elucidando os aspectos referentes às diferenças ao longo da distribuição de rendimentos e às diferenças por gênero quanto à inserção entre trabalho formal e informal, bem como suas mudanças no período recente. Ademais, busca-se avançar quanto ao procedimento adotado para a correção de seleção amostral no contexto de regressão quantílica, a partir do uso de um modelo Logit Multinominal para a estimação da equação de seleção, bem como no que se refere à utilização dos microdados dos Censos Demográficos de 2000 e 2010.

Dessa maneira, além desta introdução, este estudo se encontra estruturado em mais quatro seções. Na segunda seção, realiza-se uma breve revisão da literatura empírica, nacional e internacional, sobre o tema. Na terceira, são apresentadas a base de dados e algumas estatísticas descritivas, bem como são demonstrados os procedimentos metodológicos adotados. A quarta seção se destina a apresentação e discussão dos resultados encontrados. E, por fim, na quinta seção, são tecidas algumas considerações finais.

\section{EVIDÊNCIAS EMPÍRICAS}

As evidências empíricas acerca da informalidade do trabalho para diferentes economias e contextos corroboram com as distintas perspectivas teóricas pelas quais ela é observada. Entre os estudos que corroboram com a abordagem dualista da estrutura produtiva, a partir da estimação de diferenciais de salários, destacam-se Souza (1980) e Uthoff (1983) para o contexto dos países em desenvolvimento, e Osterman (1975) e Dickens e Lang (1985) para mercado de trabalho norte americano.

Em contrapartida à visão dualista, Maloney (1999) refuta a hipótese de que há uma "fila por emprego" no setor formal da economia mexicana, a partir da utilização de matrizes de transição e um modelo Logit Multinominal. Em trabalho posterior, Bosch e Maloney (2007) analisando a dinâmica do trabalho no Brasil, Argentina e México para os anos 1990, concluem que as transições em direção ao trabalho por conta própria são voluntárias, enquanto que os fluxos de entrada no emprego assalariado informal aparentam ser o resultado da ausência de melhores alternativas de emprego, ou seja, o comportamento do emprego informal se aproximaria da visão de "fila" ou "racionamento" no setor formal.

Arias (2007), a partir do uso de um método de decomposição de diferenciais, encontra resultados semelhantes para Argentina, Bolívia e República Dominicana. Contudo, as motivações se mostram distintas nos diferentes pontos da distribuição dos rendimentos. As evidências sugerem que apenas os trabalhadores "self-employeds" que 
se encontram nos estratos de renda mais altos têm motivações voluntárias para participação na economia informal, enquanto os empregados assalariados informais tendem a ser excluídos de empregos mais desejáveis na economia formal.

Na literatura nacional não há um consenso quanto a existência ou não de segmentação no mercado de trabalho. Do ponto de vista dos diferencias de rendimento e a partir da análise do papel de características não observáveis sobre os diferenciais entre os setores formal e informal, Carneiro e Henley (2001) e Menezes-Filho et al. (2004) defendem a hipótese de que a informalidade pode ser uma decisão voluntária resultante da avaliação de seu custo-benefício relativo à formalidade. Os resultados de Curi e Menezes-Filho (2006) apontam para uma redução significativa dos diferenciais, sugerindo uma baixa segmentação do mercado de trabalho brasileiro.

Os trabalhos de Fontes e Pero (2008) e Fontes (2009), por outro lado, apresentam evidências contrárias para o período de 2002 a 2007, na medida em que os resultados indicam um aumento dos diferenciais de rendimentos no que se refere às transições entre emprego formal e informal, ou seja, quanto aos ganhos relativos à transição do emprego informal para o formal e às perdas no sentido inverso. A partir do uso de métodos de decomposição dos diferenciais de rendimento, os trabalhos de Ulyssea (2007) e de Tanuri-Pianto e Pianto (2002) apontam evidências de segmentação. No último caso, os autores mostram que diferenciais são explicados, principalmente, pelas diferenças nos atributos dos trabalhadores, com exceção dos indivíduos com menor renda, sugerindo que os diferenciais entre os trabalhadores situados na base da distribuição corroboram com a hipótese de segmentação. Machado, Oliveira e Antigo (2007) encontram evidências de que o efeito da variação relativa das características observadas contribuiu para aumentar o diferencial entre os setores, a favor do setor formal, até a mediana da distribuição, e para diminuir o diferencial nos quantis superiores.

A ausência de consenso na literatura nacional quanto à presença ou não de segmentação no mercado de trabalho se deve, em parte, à diferenciação com relação ao conceito de trabalho informal bem como aos métodos utilizados, mas reflete principalmente a própria heterogeneidade estrutural do mercado de trabalho brasileiro, tanto com relação à força de trabalho como aos diferentes segmentos da economia. Isto é, as desigualdades podem estar relacionadas tanto às características da oferta como da demanda por trabalho, o que no caso brasileiro torna as relações formais-informais ainda mais complexas.

Embora alguns estudos apresentem avanços com relação ao uso de métodos de decomposição que permitem captar os diferenciais quanto ao papel de ambas as dimensões (oferta e demanda) sobre a determinação da renda entre trabalho formal e informal, há limitações no que se refere aos efeitos das mudanças nesses componentes sobre os diferenciais de rendimentos ao longo da distribuiçãoe quanto à desagregação da análise por 
gênero ${ }^{1}$. Especialmente em um contexto de importantes transformações no mercado de trabalho brasileiro, como o da década de 2000, associadas tanto à expansão do emprego formal quanto às mudanças de composição da população ocupada.

Desde os seminais estudos de Oaxaca (1973) e Blinder (1973), o crescimento da pesquisa relacionada aos diferenciais salariais em países desenvolvidos e em desenvolvimento tem sido profícuo. Métodos modernos que vão além da decomposição dos diferenciais na média salarial têm sido propostos. A principal vantagem desses métodos consiste em identificar os fatores que afetam os diferenciais entre dois ou mais grupos em diferentes pontos da distribuição de rendimentos. Em particular, algumas técnicas permitem realizar a decomposição dos diferenciais ao longo da distribuição de rendimentos, a partir da construção de uma distribuição contrafactual. O métodos mais conhecidos são os propostos por Juhn, Murphy e Pierce (1933), DiNardo, Fortin e Lemieux (1996), Machado e Mata (2005) e Firpo, Fortin e Lemieux (2009).

Amplamente utilizado em diversas aplicações, o método de Machado e Mata (MM) se baseia na estimação de distribuições salariais marginais consistentes com uma distribuição condicional estimada por regressão quantílica, bem como uma distribuição salarial contrafactual. Os autores aplicam o método para verificar as mudanças nas distribuições de rendimentos entre 1986 e 1995 em Portugal. Albrecht et al. (2009) propiciam maior sustentação teórica ao método MM, utilizando-o para estimar o diferencial salarial por gênero na Holanda, e evidenciando a consistência e normalidade assintótica dessa técnica, além de levar em consideração a existência de seleção amostral. Paredes (2012) também analisa a discriminação por gênero no Chile usando o método MM, enquanto Badel e Peña (2012) usam a extensão do método,proposta por Albrecht et al. (2009), para decompor o diferencial por gênero na Colômbia. Já Christofides e Michael (2013) utilizam o método para decompor o diferencial de rendimentos entre setor público e privado para 27 países europeus.

Para o Brasil, Santos e Ribeiro (2006) exploram os diferenciais salariais por gênero usando a decomposição MM, enquanto Salardi (2012) analisa os diferenciais salariais tanto por gênero como por raça, usando a decomposição $\mathrm{MM}$ e outros métodos (MELLY, 2005; FIRPO, FORTIN e LEMIEUX, 2009). Belluzzo et al. (2005) também utilizam o método MM para verificar o diferencial de rendimentos entre setor público e privado no Brasil. Quanto à análise das diferenças entre trabalho formal e informal,

\footnotetext{
Entre os trabalhos que realizam a decomposição para as mudanças na primeira metade da década de 2000, no trabalho de Ulyssea (2007) a decomposição é realizada apenas para a média dos rendimentos, enquanto que com relação ao trabalho de Machado, Oliveira e Antigo (2007), embora se considere os diferenciais ao longo da distribuição dos rendimentos, utiliza-se um método de decomposição para a média. Em ambos os casos a análise não é desagregada por gênero.
} 
poucos estudos têm investigado os diferenciais de rendimentos para o Brasil usando métodos de decomposição, limitando-se à análise dos efeitos médios, como mencionado anteriormente.

Nesse sentido, o presente trabalho visa contribuir para um melhor entendimento acerca do papel das mudanças na demanda e oferta de trabalho sobre a desigualdade entre ocupação formal e informal no Brasil na década de 2000, elucidando os aspectos referentes às diferenças ao longo da distribuição de rendimentos, por meio do uso do método MM, e às diferenças por gênero quanto à inserção ocupacional. Além disso, busca-se avançar quanto ao procedimento de correção para a seleção amostral no contexto de regressão quantílica, a partir do uso de um modelo Logit Multinominal para a decisão de participação no mercado de trabalho, ainda pouco explorado na literatura.

\section{METODOLOGIA}

\subsection{DESCRIÇÃO DOS DADOS}

A base de dados utilizada no presente trabalho consiste dos microdados dos Censos Demográficos referentes aos anos de 2000 e 2010, disponibilizada pelo Instituto Brasileiro de Geografia e Estatística (IBGE). O Censo Demográfico reporta as características socioeconômicas e demográficas da população ocupada em todo o território nacional, a um nível geográfico mais desagregado com relação às outras pesquisas domiciliares, abrangendo até os municípios, o que permite um retrato mais completo do comportamento do mercado de trabalho em termos das mudanças na desigualdade entre trabalho formal e informal para o período proposto. São utilizados os dados referentes à População Economicamente Ativa (PEA), ocupada em atividades não agrícolas e remuneradas, e residente nos setores urbanos do País, cuja idade varie entre 25 e 59 anos.

A partir da abordagem das relações de trabalho, o trabalho informal é definido de acordo com as categorias de posição na ocupação e com a natureza formal ou informal. Na literatura nacional, a definição mais utilizada é a que diferencia o trabalho formal do informal pela posse ou não de carteira assinada e/ou pela posição de trabalho por conta própria. O presente trabalho entende que estas categorias constituem formas distintas de inserção da força de trabalho e, portanto, devem ser analisadas de forma desagregada.Tendo em vista que a análise aqui proposta parte da percepção da precariedade do trabalho, cujas relações de emprego não estão sujeitas à legislação trabalhista, a definição de trabalho informal adotada compreende os empregados as- 
salariados que não possuem carteira de trabalho assinada (domésticos e não domésticos $)^{2}$. O trabalho formal, por sua vez, compreende os empregados assalariados com carteira assinada (domésticos e não domésticos) e os funcionários públicos e estatutários. Ademais, deve-se ressaltar que a análise é desagregada por gênero.

Entre 2000 e 2010 a taxa de participação do emprego sem carteira no total do emprego (soma dos empregados com e sem carteira) apresentou redução em torno de $14 \%$, passando de $30 \%$ para $25,84 \%$. Entre as mulheres essa parcela reduziu de $32,5 \%$ para $29,4 \%(-9,5 \%)$, enquanto que entre os homens a redução foi de $27,5 \%$ para $22,87 \%$ $(-16,83 \%)$. Se considerado o total da ocupação (somados empregados com e sem carteira e dos trabalhadores por conta própria), a participação do emprego sem carteira diminuiu de $20,81 \%$ para $18,88 \%$, enquanto que a do trabalho por conta própria passou $23,55 \%$ para $16,86 \%$. Esta queda da informalidade pode ser associada ao crescimento do emprego formal, que respondeu por cerca $86 \%$ do aumento na taxa de ocupação no período.

No que se refere à composição da amostra, para o trabalho formal e o informal, a Tabela 1 apresenta a descrição segundo as características de ambos os grupos e segundo o sexo. Para ambos os grupos, tanto para o trabalho feminino como para o masculino, houve um aumento da idade média dos trabalhadores e da proporção de negros e pardos, em decorrência do aumento da participação desses grupos no total da ocupação. Tanto entre as mulheres como entre os homens, os trabalhadores formais são mais escolarizados do que os informais, contudo, com relação à média para o período, o nível de escolaridade dos últimos cresceu mais do que para os primeiros.

Tanto em 2000 como em 2010 parte significativa das mulheres ocupadas formalmente (mais de 70\%) se concentrava, por ordem de importância, nos setores de Serviços Sociais, Serviços Pessoais e Serviços Distributivos. Quanto às empregadas informais, 63\% delas se encontrava ocupada unicamente no setor de Serviços Pessoais. Entre os homens ocupados formalmente, destacam-se no período os setores de Serviços Distributivos e Serviços Produtivos. Enquanto que os empregados informais se concentram, majoritariamente, nos Serviços Distributivos e na Construção Civil.

\footnotetext{
2 A lógica de inserção do trabalho por conta própria se dá pela estratégia ocupacional, seja pelo fator sobrevivência ou pelo fator escolha. Nesse caso, o critério não é o ambiente legal no qual se inserem essas ocupações, mas por constituírem formas de organização da produção com pouca ou nenhuma diferenciação entre capital e trabalho.
} 
Tabela 1 - Média do rendimento/hora e composição da amostra', trabalho formal e informal, mulheres e homens de 25 a 59 anos, Brasil, 2000/2010

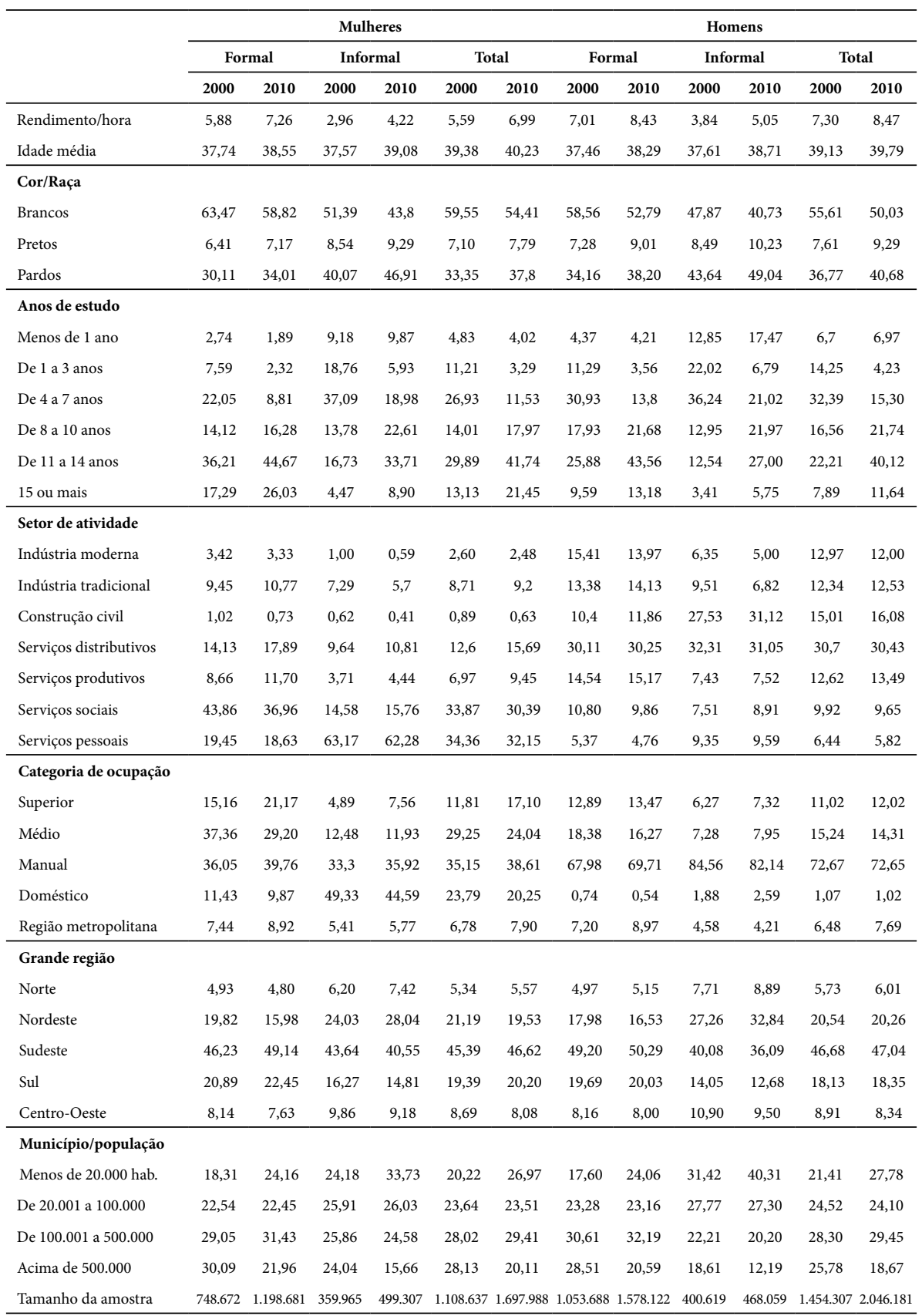

Nota: Com exceção da idade, a composição da amostra quanto às demais variáveis se refere ao valor percentual. Fonte: Elaboração própria, a partir dos dados dos Censos Demográficos 2000/2010. 
No que tange ao perfil ocupacional, entre as mulheres, houve um aumento da participação das ocupações de nível superior no emprego formal em detrimento da participação das ocupações de nível médio, enquanto que para o emprego informal uma redução na proporção de domésticas e um aumento da participação das ocupações manuais e superiores. Entre os homens, empregados formais e informais se inserem, predominantemente, em ocupações manuais, contudo, entre os primeiros há uma maior participação relativa das ocupações de nível médio e superior.

Quanto à composição por recortes regionais não houve alteração significativa, com uma concentração dos trabalhadores nas regiões não-metropolitanas e na região Sudeste, sendo a proporção dos trabalhadores formais nesta região acima da média e nas regiões Norte e Nordeste abaixo da média. No que se refere aos municípios, os trabalhadores formais e informais se encontram relativamente bem distribuídos segundo o porte dos municípios.

Com relação à variação nos rendimentos, na média houve uma redução no diferencial dos rendimentos/hora entre emprego formal e informal, em torno de $15 \%$ entre as mulheres e de $9 \%$ entre os homens. No caso feminino, o rendimento no emprego informal correspondia a $50 \%$ do rendimento no emprego formal, em 2000, enquanto em 2010 essa razão passou a ser de 58\%. No caso masculino, os empregados informais ganhavam cerca de $55 \%$ do valor do rendimento/hora dos empregados formais, ao passo que em 2010 essa razão passou a ser de $60 \%$.

Quanto aos diferenciais ao longo da distribuição de rendimentos, as estimativas da densidade de Kernel possibilitam uma descrição mais elucidativa com respeito às possíveis mudanças nos diferenciais entre trabalho formal e informal. Como mostra a Figura 1, a distância horizontal fornece as medidas dos diferenciais ao longo dos percentis da distribuição. Tanto para o trabalho feminino como para o masculino, nos dois pontos do tempo, verificam-se vantagens de rendimento para o emprego formal em qualquer ponto da distribuição, entretanto, observa-se uma redução desses diferenciais no período, com exceção das bases da distribuição, que se mantêm mais afastadas. Contudo, nota-se que os diferenciais entre os homens são menores do que os apresentados entre as mulheres.

De maneira geral, os dados apresentados indicam que o processo de expansão do grau de formalização ao longo da década de 2000 foi acompanhado por mudanças no perfil dos trabalhadores formais e informais, alterando a composição relativa entre os grupos. As mudanças mais significativas no perfil dos trabalhadores formais e informais se referem ao grau de escolaridade, que se mostram as mais expressivas em termos da redução da heterogeneidade entre os grupos. Além disso, mudanças nos diferenciais de rendimentos sinalizam para possíveis diferenças quanto à redução da desigualdade entre os gruposnos diferentes pontos da distribuição dos rendimentos. 
Figura 1 - Densidade Kernel para o log do salário/hora dos empregados formais e informais, mulheres e homens ocupados de 25 a 59 anos, Brasil, 2000/2010
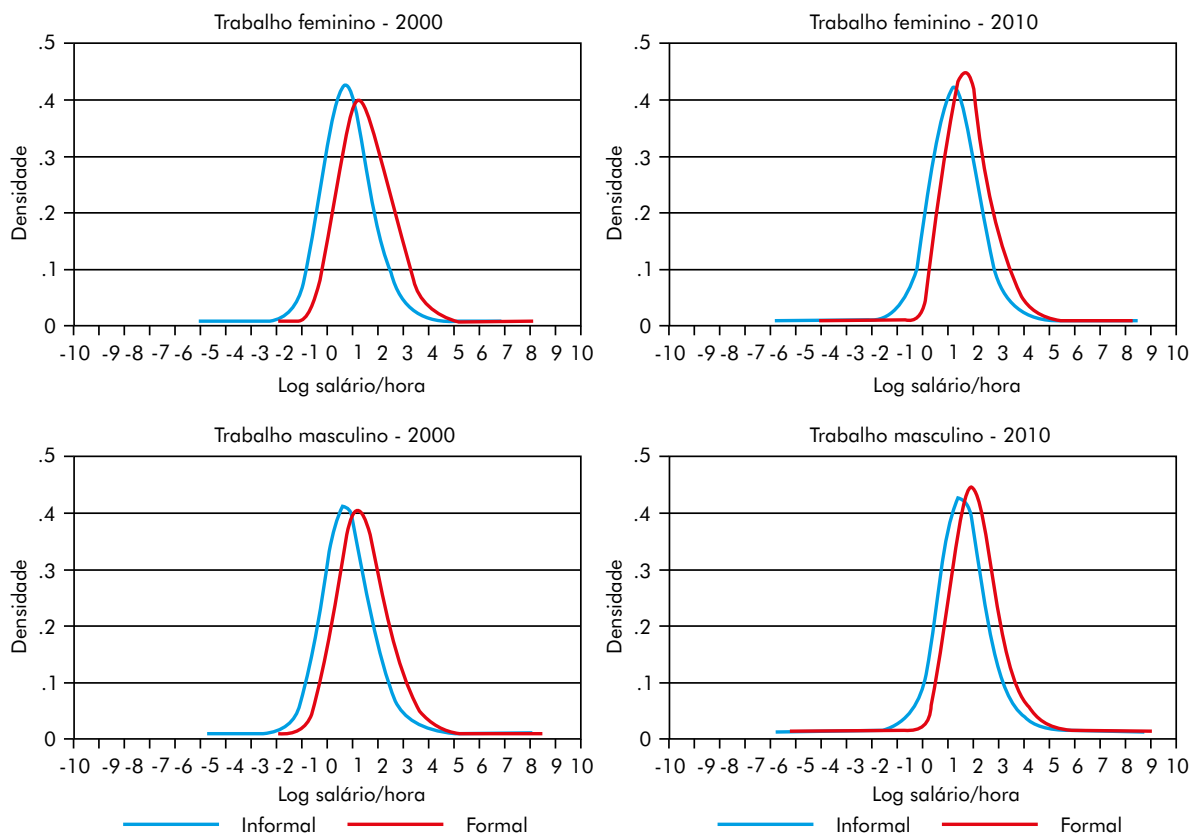

kernel $=$ epanechnikov, bandwidth $=0.5450$

Fonte: Elaboração própria, a partir dos dados dos Censos Demográficos 2000 e 2010.

\subsection{DECOMPOSIÇÃO DOS DIFERENCIAIS DE RENDIMENTOS}

A análise das mudanças na desigualdade entre trabalhadores formais e informais é realizada por meio do uso dos dados dos Censos Demográficos de 2000 e 2010 e do método de decomposição de Machado e Mata (2005), que permite avaliar quanto da variação nos diferenciais de rendimentos ao longo de toda a distribuição se deve às mudanças na composição relativa entre trabalhadores formais e informais e quanto é devida à segmentação no mercado de trabalho.

O efeito "composição" reflete a heterogeneidade no mercado de trabalho quanto à natureza formal-informal das ocupações, ou seja, capta as diferenças entre os trabalhadores em termos de seus atributos individuais (raça, escolaridade, etc.), ocupacionais (setor de atividade e categoria de ocupação) e regionais, que se traduzem em diferenciais salariais dada a possibilidade de prevalência de melhores características para um grupo relativamente ao outro. Assim, o efeito "composição" permite avaliar o quanto a desigualdade diminuiu (ou aumentou) em razão de uma menor (ou maior) heterogeneidade entre os grupos. 
O efeito "segmentação" representa a segmentação no mercado de trabalho em razão da natureza formal-informal das ocupações, ou seja, indivíduos com os mesmos atributos receberiam remunerações distintas de acordo com a natureza da ocupação na qual se encontram. Isto é, a desigualdade se estabelece em decorrência de diferenças entre trabalho formal e informal quanto aos retornos a esses atributos. A variação na desigualdade devida a esse efeito reflete, portanto, mudanças nos mecanismos de determinação dos salários, que compreendem um conjunto de fatores econômicos, institucionais, sociais e políticos, de ordens estrutural e conjuntural, que moldam a estrutura das relações de produção, dado o processo de desenvolvimento capitalista e, por conseguinte, a estrutura do mercado de trabalho.

Ao se tratar da estimação de equações de rendimentos, incorre-se ao problema de seleção amostral, em que os rendimentos são observados com base na decisão de oferta de trabalho. Ademais, os fatores não observados que influenciam a decisão de participação no trabalho informal são distintos daqueles relacionados à participação no trabalho formal. Dessa maneira, utiliza-se a abordagem de Dubin e McFadden (1984) para a correção de seleção amostral, que consiste de um procedimento em dois estágios, cuja a estimação da equação de seleção no primeiro estágio é baseada no uso de um modelo Logit Multinominal, que envolve a decisão entre a participação na força de trabalho formal ou informal versus a não participação.

Entende-se que o erro de especificação derivado da não consideração da seleção amostral seria excessivamente prejudicial à análise. Contudo, não há uma abordagem de regressão quantílica amplamente aceita na presença de seleção amostral e a literatura sobre estes modelos é escassa. Buchinsky $(1998,2001)$ propõe uma abordagem aditiva para corrigir a seleção de amostras na regressão quantílica. Huber e Melly (2015) consideram um modelo de quantil mais geral, não aditivo, se concentrando em testes de aditividade. Também estão relacionados Neal (2004) e Olivetti e Petrongolo (2008), os quais aplicam métodos de imputação, e Picchio e Mussida (2010), que propõem um modelo paramétrico. Lee (1983) e Smith (2003) discutem métodos de correção de seleção distribucional paramétrica.

A maioria das abordagens de correção de seleção se concentra na estimativa de modelos de médias condicionais. Em muitas aplicações, no entanto, uma especificação flexível de toda a distribuição de resultados é de interesse. Arellano e Bonhomme (2017) propõem um método de correção de seleção para modelos de regressões quantílicas, avançando na proposição metodológica, por meio de uma função de distribuição bivariada acumulada do erro na equação de resultados e na equação de seleção, estimando os parâmetros pela minimização de um critério de método de momentos. Outros trabalhos tratam da correção do viés de seleção dentro das estruturas de decomposição, tais como Dolton, Makepeace e Van Der Klaauw (1989), Neuman e Oa- 
xaca (2004), e Bourguignon, Fournier e Gurgand (2007). Carneiro e Henley (2001) exploram diferenças salariais entre os setores formal e informal enquanto controlam o viés de seleção, bem como Cacciamali, Tatei e Rosalino (2009).

A correção de seleção dentro de técnicas de decomposição é reconhecidamente complexa, e sua aplicação em uma estrutura quantílica é ainda mais complexa. Soluções propostas são a adoção de uma função de controle ou o uso de métodos de variáveis instrumentais, garantindo uma identificação robusta dos componentes da decomposição. Alguns estudos tentam explicar a seleção amostral ao implementar técnicas de decomposição de quantis (ALBRECHT, van VUUREN e VROMAN, 2009; NICODEMO, 2009; CHZHEN, MUMFORD e NICODEMO, 2012). Esses estudos aplicam uma adaptação semi-paramétrica do procedimento paramétrico de Heckman para regressões quantílicas, como proposto por Buckinsky (1998) ${ }^{3}$. Como aponta Salardi (2012), qualquer correção de seleção dentro de uma estrutura quantílica tem desafios significativos, juntamente com a questão geral da validade dos instrumentos. Estes incluem a escolha do método de estimação apropriado para o primeiro estágio e o problema da identificação do intercepto da equação salarial, como discutido em Andrews e Schafgans (1998) e Buckinsky (1998).

O presente trabalho entende que a seleção entre trabalho formal e informal se dá por um processo de escolha simultânea, utilizando-se, portanto, de um modelo de escolha discreta multinomial no primeiro estágio. O segundo estágio envolve a estimação da equação de rendimentos com a introdução dos termos de correção. Assim, o modelo geral pode ser especificado como:

$$
\begin{gathered}
y_{j}=x \beta_{j}+u_{j} \\
y_{j}^{*}=z \gamma_{j}+\eta_{j}
\end{gathered}
$$

Em (1) e (2), $j=0,1,2$, descreve as alternativas de seleção, em que $j=0$ representa a não participação no mercado de trabalho, $j=1$ a participação no trabalho formal, e $j=2$ a participação no trabalho informal, de modo que $y_{j}^{*}$ é uma variável categórica que determina a escolha individual entre as múltiplas alternativas e $z$ é um conjunto de variáveis determinantes da decisão de participação. A variável de resultado, $y_{j}$, é o logaritmo do

\footnotetext{
3 Tal método é utilizado nas situações em que a seleção se dá em um processo de escolha binária. Uma aplicação para o Brasil foi feita por Tannuri-Pianto e Pianto (2002) para análise do diferencial salarial entre empregados com e sem carteira, estimando a equação de seleção a partir de um modelo de escolha entre a participação no trabalho formal versus informal.
} 
rendimento/hora e é observada somente se as categorias 1 ou 2 forem escolhidas; $x$ é um vetor de características observáveis;e o termo de erro $u_{j}$ satisfaz $E\left(u_{i} \mid x, z\right)=0$ e $V\left(u_{j} \mid x, z\right)=\sigma^{2}$.

As variáveis utilizadas no presente trabalho são definidas de forma que:

- $X$ compreende variáveis individuais como cor/raça, idade, idade ao quadrado, grau de escolaridade; variáveis regionais, como dummy para região metropolitana/não-metropolitana, grande região e tipo de município (pelo tamanho da população); e variáveis ocupacionais, como setor de atividade e categoria de ocupação.

- $Z$ é representado por variáveis individuais, como cor/raça, idade, idade ao quadrado, grau de escolaridade; variáveis regionais como dummy para região metropolitana/não metropolitana, grande região e tipo de município (pelo tamanho da população); e variáveis familiares, como dummy para a presença de cônjuge, presença de filhos de até 6 anos e presença de filhos de 7 a 14 anos.

No entanto, considerando que o termo de erro pode não ser independente dostermos $\left(n_{j}\right)$, Dubin e McFadden (1984) adotam uma abordagem baseada na hipótese de linearidade entre os termos de erro, expressa em termos da média de $u_{1}$ condicional aos termos $\left(n_{j}\right)$ :

$$
E\left(u_{1} \mid \eta_{1} \ldots \eta_{M}\right)=\sigma \sum_{j=1 \ldots M} r_{j}\left(\eta_{j}-E\left(\eta_{j}\right)\right), \operatorname{com} \sum_{j=1 \ldots M} r_{j}=0
$$

Em (3), $r_{j}$ representa a correlação entre $u_{1}$ e $\left(\eta_{j}-\eta_{1}\right)$. Esta hipótese implica que:

$$
E\left(u_{1} \mid \eta_{1} \ldots \eta_{M}\right)=\sigma \sum_{j=2 \ldots M} r_{j}\left(\eta_{j}-\eta_{1}\right)
$$

Desse modo, a esperança condicional para a probabilidade de resposta $(j=1)$ do modelo Logit Multinomial no primeiro estágio pode ser definida como:

$$
E\left(\eta_{j}-\eta_{1} \mid y_{1}^{*}>\max _{s \neq 1}\left(y_{s}^{*}\right), \Gamma\right)=\frac{P_{j} \ln \left(P_{j}\right)}{1-P_{j}}+\ln P_{1}, \quad \forall j>1
$$


Dada a hipótese de linearidade, a equação de salários pode então ser estimada como segue:

$$
y_{1}=x_{1} \beta_{1}+\sigma \sum_{j=0,2} r_{j}\left(\frac{P_{j} \ln \left(P_{j}\right)}{1-P_{j}}+\ln P_{1}\right)+w_{1}
$$

Os termos de erro da equação de seleção são normalizados, de modo que há $M-1$ parâmetros de correção na equação (6), ou seja, se houver três alternativas no modelo de decisão, haverá dois termos de correção na equação de salários.

Tendo em vista que o objetivo deste trabalho é a correção do viés de seleção no contexto de regressão quantílica, a equação (6) deve ser especificada em tais condições.O modelo de regressão quantílica introduzido por Koenker e Bassett (1978) tem como ponto de partida a definição dos quantis amostrais de uma variável aleatória $Y$ com função de distribuição $F(Y)$. Então, o $\theta^{\circ}$ quantil amostral, $0<\theta<1$, é definido como a solução ao problema de minimização da soma ponderada dos valores absolutos dos resíduos:

$$
\min _{b}\left[\sum_{i=y_{i} \geq b} \theta\left|y_{i}-b\right|+\sum_{i=y_{i}<b}(1-\theta)\left|y_{i}-b\right|\right]
$$

Substituindo $b$ por uma função linear de covariáveis, a $\theta^{\circ}$ regressão quantílica pode ser definida como:

$$
\min _{\beta} \frac{1}{n}\left[\sum_{i=y_{i} \geq x_{i} \beta} \theta\left|y_{i}-x_{i} \beta\right|+\sum_{i=y_{i}<x_{i} b}(1-\theta)\left|y_{i}-x_{i} \beta\right|\right]
$$

Assim, reescrevendo a equação (6) condicionada à alternativa 1 , na forma de regressão quantílica, tem-se que:

$$
y_{1}=x_{1}^{\prime} \beta_{1 \theta}+\sigma \sum_{j=0,2} r_{j}\left(\frac{P_{j} \ln \left(P_{j}\right)}{1-P_{j}}+\ln P_{1}\right)+w_{1 \theta,} \quad(0 \leq \theta \leq 1)
$$


Em (9), $w_{1 \theta} \equiv x_{1}^{\prime}\left(\beta_{o}-\beta_{\theta}\right)+u$ e o $\theta^{\circ}$ quantil condicional de $y_{1}$ sobre $x_{1}$ corresponde a Quant $_{\theta}\left(y_{1} \mid x_{1}\right)=x_{1}^{\prime} \beta_{1 \theta}$, tal que Quant $_{\theta}\left(w_{1 \theta} \mid x_{1}\right)=0$. O modelo pode ser então especificado como:

$$
\ln y_{i t}=\mathrm{x}_{i t} \beta_{\theta}+\sigma_{\theta} m_{1 i t}+\sigma_{\theta} m_{2 i t}+w_{\theta i t}
$$

Em (10), ln $y_{i t}$ é o logaritmo do rendimento/hora nos diferentes quantis da distribuição, para os trabalhadores formais ou informais, nos dois pontos do tempo; $\mathrm{x}_{i t}$ é um vetor de características observáveis, descritas anteriormente; e $m_{1 i t}$ e $m_{2 i t}$ representam os termos de correção para o viés de seleção ${ }^{4}$. Dessa maneira, estimadas as regressões quantílicas, com correção para seleção amostral, separadamente para os trabalhadores formais e para os informais e por gênero, para os dois pontos do tempo, parte-se então para a decomposição dos diferenciais de rendimentos entre os grupos.

O método de Machado e Mata (2005) é baseado na estimação de funções de densidade marginal dos salários consistentes com as distribuições condicionais de ambos os grupos (estimadas por regressão quantílica) e com a distribuição contrafactual de um dos grupos. A decomposição consiste da comparação entre as distribuições marginais resultantes. No caso deste estudo, a decomposição envolve a criação de uma distribuição salarial para os trabalhadores informais na situação contrafactual de trabalho formal, que é subsequentemente comparada com as distribuições marginais geradas para ambos os grupos com base em suas respectivas distribuições condicionais.

As distribuições resultantes, $f^{*}(\hat{y}(1)), f^{*}(\hat{y}(2))$ e $f^{*}\left(\hat{y}^{*}(2)\right)$, respectivamente para trabalho formal, informal e contrafactual, são utilizadas para decompor os diferencias entre as distribuições observadas dos grupos, $f(y(1))$ e $f(y(2))$. Dado que $f^{*}(\hat{y}(1))$ e $f^{*}\left(\hat{y}^{*}(2)\right)$ são estimadas utilizando os mesmos coeficientes, as diferenças entre essas distribuições em cada quantil podem ser atribuídas às diferenças nas características observáveis. De modo similar, a comparação entre $f^{*}(\hat{y}(2))$ e $f^{*}\left(\hat{y}^{*}(2)\right)$ fornecem a diferença que é causada pelas diferenças nos coeficientes, uma vez que ambas as distribuições são estimadas utilizando as mesmas características.

4 Os termos de correção e $m_{1 i t}$ e $m_{2 i t}$ são condicionados às probabilidades de resposta $(j=1)$ e $(j=2)$, respectivamente, tendo como base a alternativa $(j=0)$. Como já demonstrado anteriormente, em razão da normalização dos termos de erro, há $M-1$ parâmetros de correção na equação de resultado, ou seja, há apenas 2 parâmetros no caso de 3 alternativas. 
Assim, considerando $Q_{i}(\hat{y})$ o $\theta^{\circ}$ quantil da distribuição de $\hat{y}(1), \hat{y}(2)$ e $\hat{y}^{*}(2)$, a decomposição do diferencial de salários entre trabalhadores formais e informais em cada quantil, ou seja, da diferença observada $Q(y(1))-Q(y(2))$ pode ser escrita como:

$$
Q(y(1))-Q(y(2))=\left[Q_{i}(\hat{y}(1))-Q_{i}\left(\hat{y}^{*}(2)\right)\right]+\left[Q_{i}\left(\hat{y}^{*}(2)\right)-Q_{i}(\hat{y}(2))\right]
$$

Em (11), $\left[Q_{i}(\hat{y}(1))-Q_{i}\left(\hat{y}^{*}(2)\right)\right]$ representa a parte do diferencial no $\theta^{\circ}$ quantil da distribuição que é devida às diferenças entre os trabalhadores em termos de seus atributos observáveis, enquanto que $\left[Q_{i}\left(\hat{y}^{*}(2)\right)-Q_{i}(\hat{y}(2))\right]$ fornece a parte do diferencial que é causada pelas diferenças nos retornos a esses atributos, ou seja, esses dois componentes representam, respectivamente, os efeitos "composição" e "segmentação" nos diferentes pontos da distribuição dos rendimentos.

\section{RESULTADOS E DISCUSSÕES}

Nesta seção são apresentados os resultados para as mudanças recentes nos diferenciais de rendimentos entre trabalho formal e informal, separadamente por gênero. As estimativas referentes ao modelo Logit Multinominal para a correção de seleção entre a não participação no mercado de trabalho e a participação no emprego assalariado formal ou informal, para mulheres e homens separadamente, encontram-se expostas no Apêndice A (Tabela A1). Quanto às estimativas do segundo estágio referentes às regressões quantílicas para o logaritmo do rendimento/hora, as tabelas com os coeficientes e desvios-padrão também são apresentadas no Apêndice A (Tabelas A2 e A3).

É importante ressaltar que os coeficientes associados aos termos de correção se mostram estatisticamente significativos, o que revela a heterogeneidade entre os grupos quanto aos fatores não observados que influenciam a decisão de participação no mercado de trabalho, em todos os quantis da distribuição. Ademais, as variações quanto aos retornos à escolaridade entre os grupos merecem atenção especial, uma vez que esta variável se destaca como um dos principais fatores de mudanças na composição entre os grupos, podendo ter efeito significativo sobre a variação na desigualdade. Nesse sentido, convém avaliar se as alterações nos retornos a essa variável também se mostram importantes. Os coeficientes associados ao grau de escolaridadepara o logaritmo do rendimento/hora, feminino e masculino, encontram-se representados pela Figura 2. 
Para o emprego feminino, observa-se que os retornos à escolaridade são positivos, como já era esperado, ou seja, quanto maior o nível de escolaridade maiores os rendimentos, e que esses retornos aumentam ao longo da distribuição. Comparando o emprego formal e o informal, verifica-se que entre os níveis mais baixos de escolaridade, até 7 anos de estudo, as diferenças quanto aos retornos não são relevantes. A partir de 8 anos de estudo, para as mulheres nos quantis mais baixos da distribuição, nota-se uma diminuição dos retornos à escolaridade entre 2000 e 2010 para o emprego formal, ao passo que para o emprego informal ocorre o oposto. Assim, os retornos para o último passam a ser maiores do que para o primeiro.

Esse resultado sugere que em termos da educação, mantendo tudo o mais constante, o emprego informal compensa o emprego formal para a população feminina nos estratos de renda mais baixos. A partir da mediana, por outro lado, o emprego formal oferece maiores retornos à escolaridade do que o informal; contudo, há uma redução desse diferencial entre os grupos em razão, especialmente, da diminuição dos retornos no emprego formal. Com relação ao trabalho masculino, as diferenças quanto aos retornos nos quantis mais baixos da distribuição se mostram ainda menos relevantes do que o observado entre as mulheres. Em ambos os casos, à medida que os coeficientes são mais elevados nos quantis mais altos, as mudanças nos retornos à educação se mostram mais importantes para a redução da desigualdade entre os grupos nos quantis mais altos da distribuição de rendimentos.

Dessa maneira, três considerações, em particular, devem ser ressaltadas. A primeira é que a redução nos retornos à escolaridade tem como explicação plausível o aumento da oferta educacional no período, como destacado em Menezes-Filho et al. (2007). A segunda é que essa redução teve maior impacto sobre o emprego formal do que sobre o informal, tanto feminino como masculino, e representa uma diminuição da desigualdade intra-grupo. E a terceira, é que a diminuição da desigualdade intragrupo reduz a desigualdade entre os grupos, contudo, esse efeito é mais significativo nos quantis mais altos da distribuição dos rendimentos, na medida em que os retornos são significativamente mais elevados, ou seja, a demanda por educação é maior nesses quantis do que nos mais baixos. 
Figura 2 - Coeficientes da regressão para o log do rendimento/hora por escolaridade e quantil da distribuição de rendimentos, emprego formal e informal, mulheres e homens ocupados de 25 a 59 anos, Brasil, 2000/2010'
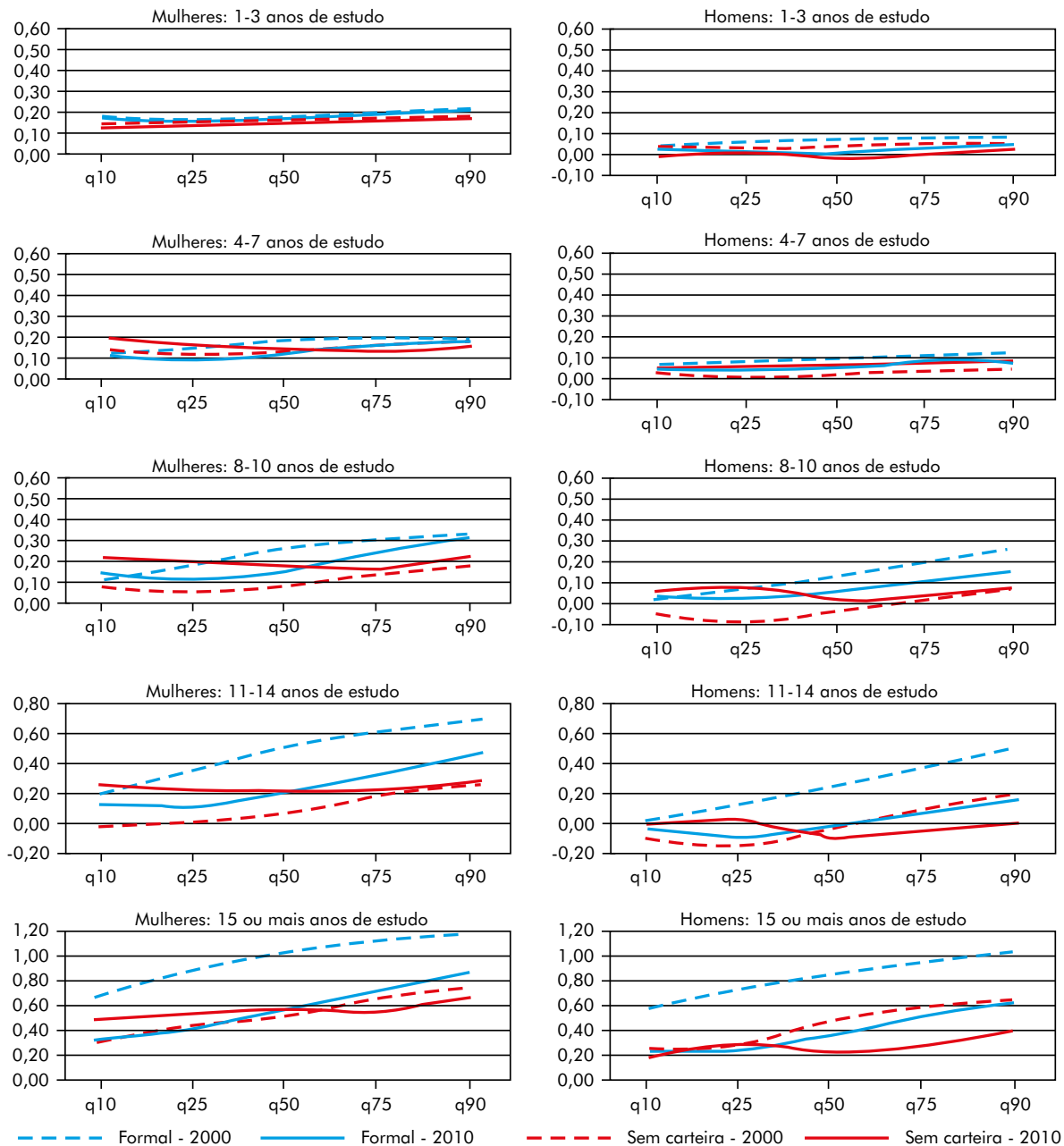

Nota: (1) Os resultados completos são apresentas no Apêndice A (Tabela A2).

Fonte: Elaboração própria, a partir dos dados dos Censos Demográficos 2000 e 2010. 
Figura 3 - Decomposição de Machado e Mata para o diferencial de rendimentos entre trabalho formal e informal, mulheres ocupadas de 25 a 59 anos, Brasil, 2000/2010
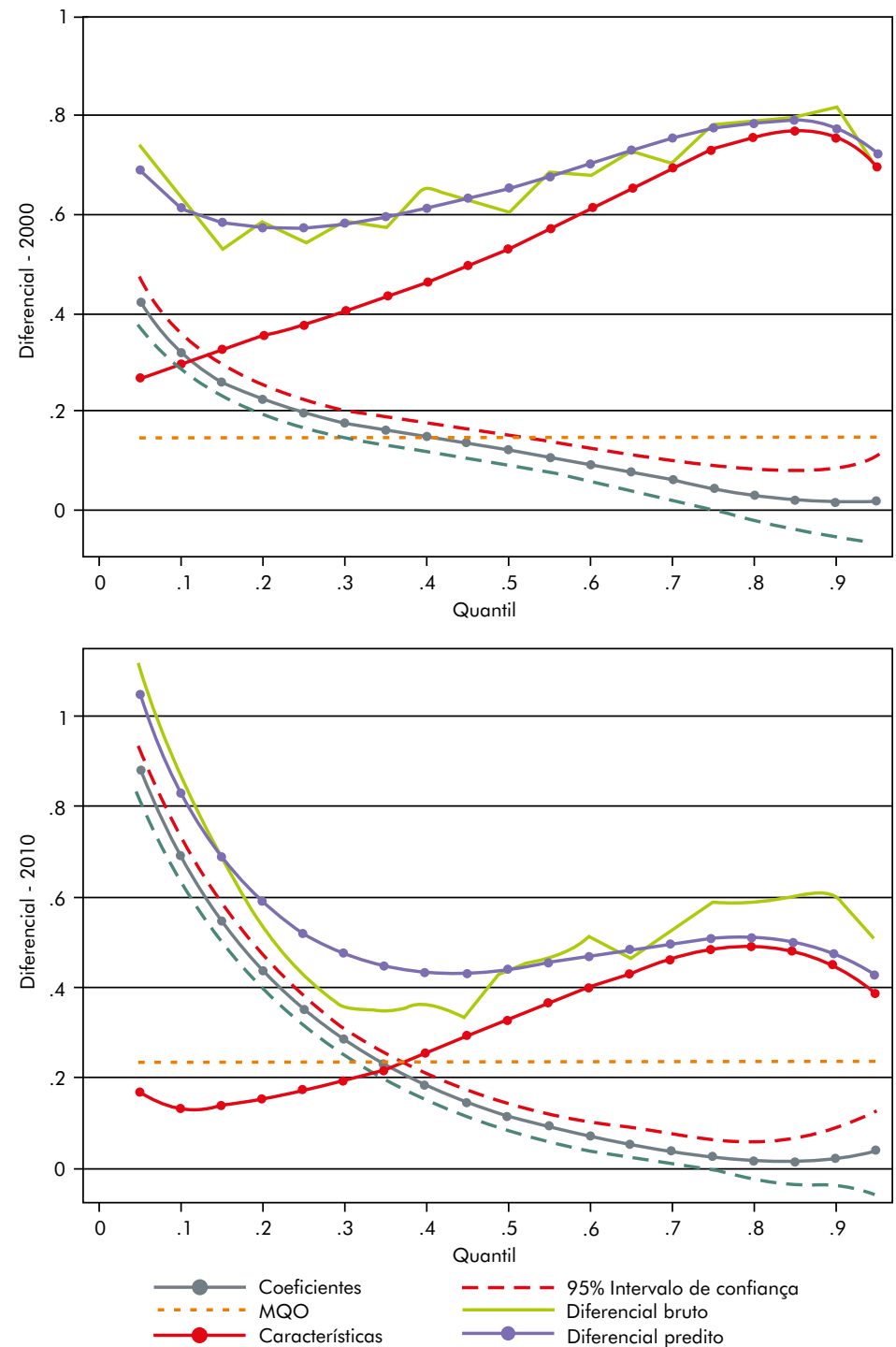

Nota: (1) A tabela completa com os valores da decomposição encontra-se no Apêndice A (Tabela A4). Fonte: Elaboração própria, a partir dos dados dos Censos Demográficos de 2000 e 2010.

Isto posto, para verificar em que medida as mudanças nos retornos, não apenas em termos da educação, ou seja, como o efeito de segmentação e o efeito de composição têm alterado a desigualdade entre os grupos ao longo de toda a distribuição, parte-se para a análise de decomposição. Os resultados para o trabalho feminino são apresen- 
tados na Figura 3. Verifica-se um aumento do diferencial de rendimentos na base da distribuição, até o $20^{\circ}$ quantil. Em 2000, as empregadas formais tinham rendimentos que variavam, do $5^{\circ}$ ao $20^{\circ}$ quantil, de $69 \%$ a $57 \%$ a mais do que as empregadas informais, enquanto que em 2010 esse diferencial passou a ser de duas vezes a $59 \%$ superior. Esse aumento é decorrente do aumento no diferencial associado aos retornos às características observáveis. Por outro lado, observa-se uma queda progressiva do diferencial total a partir do $25^{\circ}$ quantil, devida à redução das diferenças entre os grupos quanto às características observáveis, que diminui de 5 a 30 pontos percentuais no período.

No que se refere ao trabalho masculino, verifica-se pela Figura 4 que a evolução dos componentes dos diferenciais de rendimentos segue o mesmo padrão observado para o trabalho feminino. Isto é, ocorre um aumento da desigualdade entre trabalho formal e informal na base da distribuição, até o $10^{\circ}$ quantil, em razão da ampliação dos diferenciais relacionados aos retornos às características observáveis, e uma redução progressiva da desigualdade ao longo da distribuição, decorrente da diminuição dos diferenciais associados a essas características. Contudo, a desigualdade entre os homens se mostra inferior. Os diferenciais favoráveis ao emprego formal no $10^{\circ}$ quantil apresentaram um aumento de cerca de $51 \%$ para $58 \%$ no período.

Os diferenciais de rendimentos mais pronunciados entre as mulheres têm como explicação as desigualdades de gênero no mercado de trabalho, uma vez que há maior segregação ocupacional com respeito ao trabalho feminino, com a predominância das mulheres em determinadas ocupações, como é o caso do trabalho doméstico. No entanto, a despeito de um maior diferencial, a redução do efeito 'composição' se mostra maior para as mulheres do que para os homens, possivelmente um reflexo do aumento da escolaridade mais significativo para a força de trabalho feminina.

Embora as diferenças associadas às características tenham reduzido ao longo de toda a distribuição, a redução não foi suficiente para compensar o aumento do diferencial referente aos retornos na base da distribuição. Há dois padrões que devem ser observados. O primeiro diz respeito a importância do efeito de composição sobre a desigualdade de rendimentos, que aumenta ao longo da distribuição, isto é, as(os) empregadas(os) formais apresentam melhores características observáveis relativamente às(aos) empregadas(os) sem carteira conforme se avança ao longo dos quantis. Este componente reflete, em parte, o efeito da seletividade quanto à alocação entre emprego formal e sem carteira, captada pelos termos de correção. O segundo se refere à importância do efeito de segmentação, que diminui ao longo da distribuição, isto é, os retornos ao emprego formal relativamente ao emprego sem carteira diminuem. Este componente reflete, em parte, o efeito da seletividade quanto aos fatores não observados que determinam a participação no mercado de trabalho, refletindo a heterogeneidade entre os grupos e ao longo da distribuição. 
Figura 4 - Decomposição de Machado e Mata para o diferencial de rendimentos entre trabalho formal e sem carteira, homens ocupados de 25 a 59 anos, Brasil, 2000/2010'
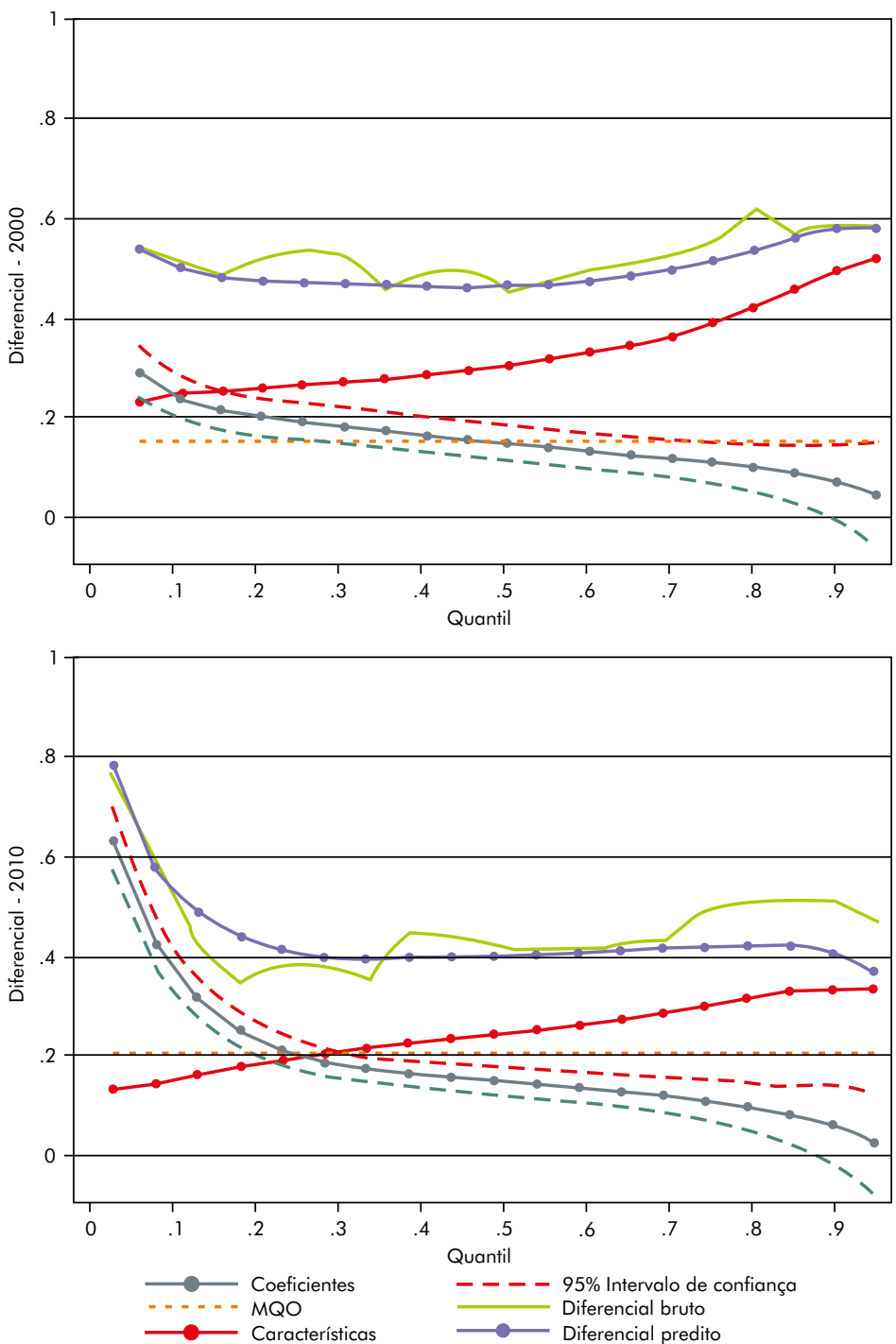

Nota: (1) A tabela completa com os valores da decomposição, encontra-se no Apêndice A (Tabela A4). Fonte: Elaboração própria, a partir dos dados dos Censos Demográficos de 2000 e 2010.

Esses resultados se assemelham, em parte, aos resultados de Tanuri-Pianto e Pianto (2002) para o Brasil, que encontram evidências de segmentação na base da distribuição salarial. Quando comparados aos resultados obtidos por Arias (2007) para a Argentina, Bolívia e República Dominicana, também se observam semelhanças, 
uma vez que os autores encontram uma clara desvantagem de rendimentos dos trabalhadores informais assalariados sem carteira, nos três países, devido às diferenças nos retornos, sendo especialmente maior nos estratos de menor renda. Em ambos os estudos, no entanto, a análise não é desagregada por gênero, que como pôde se observar, embora se constate um padrão similar, apresenta diferenças quanto ao nível e a variação na desigualdade.

\section{CONSIDERAÇÕES FINAIS}

O objetivo do presente trabalho foi verificar os efeitos das mudanças na composição relativa e na segmentação entre trabalho formal e informal sobre os diferenciais de rendimentos na década de 2000, decompondo os diferencias ao longo da distribuição de rendimentos e por gênero. Para ambos os casos analisados, emprego feminino e masculino, os resultados apontam para um aumento do diferencial de rendimentos entre os trabalhadores na base da distribuição, em razão do aumento nos diferenciais associados aos retornos às características observáveis, ou seja, ao efeito de segmentação, e uma redução progressiva do diferencial ao longo da distribuição, decorrente da redução dos diferenciais relacionados a essas características, isto é, do efeito de composição.

$\mathrm{Na}$ medida em que o efeito de composição é mais pronunciado no topo da distribuição, ou seja, que os grupos são mais heterogêneos, a redução dessas diferenças se mostra mais relevante para a redução da desigualdade no topo do que na base na distribuição. Por outro lado, uma vez que o efeito de segmentação é mais pronunciado na base da distribuição, o aumento dos retornos à formalidade relativamente à informalidade sugere que, em termos da percepção da renda, houve um aprofundamento da precariedade do emprego informal no período, especialmente para os trabalhadores nos estratos de renda mais baixos.

Contudo, constatou-se diferenças relevantes por gênero quanto à importância e variação desses componentes ao longo da distribuição. Visto que as mulheres apresentam um maior nível de desigualdade, o aumento da segmentação na base da distribuição se mostra ainda mais agravante para o trabalho informal feminino. Por outro lado, a redução no efeito de composição superior entre as mulheres ao longo de toda a distribuição acarretou em uma queda do diferencial total a partir do $30^{\circ}$ quantil maior para o trabalho feminino, ainda que este diferencial permaneça inferior para o trabalho masculino.

$\mathrm{O}$ aumento da desigualdade nos estratos de renda mais baixos tem como explicação provável a evolução do salário mínimo na última década, que se mostra como um dos fatores mais marcantes em termos da determinação da renda no período e, por- 
tanto, uma valorização relativa do emprego formal. Nesse sentido, contesta-se a hipótese de que a valorização do mínimo teria efeito semelhante sobre os rendimentos dos trabalhadores informais ${ }^{5}$. Não obstante, a redução da desigualdade, com exceção da base da distribuição, devida às variações de composição entre os grupos, revela a importância das mudanças no perfil da força de trabalho, como no que se refere ao aumento da escolaridade, por exemplo. Embora a escolaridade tenha aumentado para ambos os grupos analisados, seu crescimento mais significativo entre os trabalhadores informais do que entre os formais se mostra como o fator mais expressivo para a redução da heterogeneidade entre os grupos, sendo ainda mais relevante entre as mulheres. Contudo, embora essas mudanças ocorram ao longo de toda a distribuição, elas apresentam maiores efeitos sobre os trabalhadores nos estratos de renda mais elevada. Uma vez que nos quantis mais baixos os grupos são menos heterogêneos, esses efeitos são menos importantes e não se mostram suficientes para compensar o efeito de segmentação.

Dessa maneira, a decomposição dos diferenciais de rendimentos permitiu captar importantes mudanças quanto às diferenças de composição e de valorização entre trabalho formal e informal no Brasil ao longo da década de 2000, assim como contribui para o preenchimento de algumas lacunas, especialmente no que diz respeito à decomposição ao longo da distribuição de rendimentos e à estratégia utilizada para a correção de seletividade, bem como à desagregação da análise por gênero.

Deve-se ressaltar ainda, que há uma série de desdobramentos possíveis a partir da análise empreendida neste estudo, como a ampliação da análise para outros perfis etários, por exemplo, ou a desagregação do emprego assalariado entre emprego doméstico e não doméstico, em razão do peso da informalidade nas atividades domésticas, sobretudo para o trabalho feminino. A desagregação entre setor público e privado em função da importância do primeiro para a formalidade também representa uma opção de aprofundamento da pesquisa.

5 As razões para esses diferenciais associados à segmentação no mercado de trabalho são frequentemente apontadas pela literatura como relacionadas a fatores institucionais (FIELDS, 1990) e de mercado (SOUZA e TOKMAN, 1976; SOUZA, 1980; UTHOFF, 1983; OSTERMAN, 1975; DICKENS e LANG, 1985). No primeiro caso, destacam-se a presença de sindicatos e as leis de salário mínimo. No segundo, as próprias imperfeições do mercado, que geraria uma estrutura produtiva segmentada e, consequentemente, uma segregação ocupacional desfavorável aos trabalhadores informais. Considerando que as equações de rendimentos estimadas neste estudo são controladas para atributos de capital humano, de região e de mercado, a evolução do salário mínimo na década de 2000 se mostra como o fator mais plausível para o aumento da desigualdade na cauda inferior da distribuição dos rendimentos. 


\section{REFERÊNCIAS}

ALBRECHT, J.; VUUREN, A.V.; VROMAN, S. Counterfactual distributions with sample selection adjustments: econometric theory and an application to the Netherlands. Labour Economics, v. 16, n. 4, p. 383-396, 2009.

ANDREWS, D.W.; SCHAFGANS, M. Semiparametric estimation of the intercept model. Review of Economic Studies, v. 65, n. 3, p. 497-517, 1998.

ARELLANO, M.; BONHOMME, S. Quantile selection models with an application to understanding changes in wage inequality. Econometrica, v. 85, n. 1, p. 1-28, 2017.

ARELLANO, M.; BONHOMME, B. Sample selection in quantile regression: a survey. Working Paper, Madrid, Centro de Estudios Monetarios y Financieros, n. 1792, jan. 2017.

ARIAS, O. S. "Informality, Earnings, and Welfare". In: PERRY, G. E et al. Informality: exit and exclusion. Washington, D.C.: The World Bank, 2007, p. 79-100.

BADEL, A.; PEÑA, X. Decomposing the gender wage gap with sample selection adjustment: evidence from Colombia. Working Paper, Federal Reserve Bank of St. Louis, n. 2010-045A, October 2010.

BELLUZZO, W.; ANUATTI-NETO, F.; PAZELLO, E. T. Distribuição de salários e o diferencial público-privado no Brasil. Revista Brasileira de Economia, v. 59, n. 4, p. 511-533, 2005.

BLINDER, A. S. Wage discrimination: reduced form and structural estimates. Journal of Human Resources, v. 8, n. 4, p. 436-455, 1973.

BOSH, M.; MALONEY, W. Comparative analysis of labor market dynamics using Markov processes: an application to informality. Discussion Paper, Bonn, IZA, n. 3038, September 2007.

BUCHINSKY, M. The dynamics of changes in the female wage distribution in the USA: a quantile regression approach. Journal of Applied Econometrics, v. 13, n. 1, p. 1-30, January/February 1998.

BOURGUIGNON, F.; FOUNIER, M.; GURGAND, M. Selection bias corrections based on the multinomial logit model: Monte Carlo comparisons. Journal of Economic Surveys, v. 21, n. 1, p. 174-205, 2007.

CACCIAMALI, M. C.; TATEI, F.; ROSALINO, J. W. Estreitamento dos diferenciais de salários e aumento do grau de discriminação: limitações da mensuração padrão? Planejamento e Políticas Públicas, n. 33, p. 195-222, 2009.

CACCIAMALI, M. C. Globalização e processo de informalidade. Economia e Sociedade, v. 14, p. 153-174, jun. 2000.

CARNEIRO, F. G.; HENLEY, A. "Modelling formal vs. informal employment and earnings: microeconomic evidence for Brazil”. In: ENCONTRO NACIONAL DE ECONOMIA, 29, Salvador, 2001. Anais... Niterói: ANPEC, 2001.

CHRISTOFIDES, L. N.; MICHAEL, M. Exploring the public-private sector wage gap in European countries. IZA Journal of European Labor Studies, v. 2, n. 15, p. 1-53, 2013.

CHZHEN, Y.; MUMFORD, K.; NICODEMO, C. The gender pay gap in the australian private sector: is selection relevant across the wage distribution? Discussion Paper, Bonn, IZA, n. 6558, May 2012. 
CURY, A. A.; MENEZES-FILHO, N. A. O mercado de trabalho brasileiro é segmentado? Alterações no perfil da informalidade e dos diferenciais de salários nas décadas de 1980 e 1990. Estudos Econômicos, v. 36, n. 4, p. 867-899, out./dez. 2006.

DE SOTO, H.; GHERSI, E.; GHIBELLINI, M. El otro sendero: la revolución informal. Lima: Editorial El Barranco, 1986.

DICKENS, W. T.; LANG, K. A test of dual labour market theory. American Economic Review, v. 75, n. 4, p. 1-22, September 1985.

DINARDO, J.; FORTIN, N.; LEMIEUX, T. Labor market institutions and the distribution of wages, 1973-1992: a semi parametric approach. Econometrica, v. 64, n. 5, p. 1001-1044, 1996.

DOERINGER, P. B.; PIORE, M. J. Internal labor markets and manpower analysis. Lexington: Lexington Books, 1971.

DOLTON, P.; MAKEPEACE, G.; VAN DER KLAAUW, W. Occupational choice and earnings determination: the role of sample selection and non-pecuniary factors. Oxford Economic Papers, v. 41 n. 1, p. 573-594, 1989.

DUBIN, J. A.; McFADDEN, D. L. An econometric analysis of residential electric appliance holdings and consumption. Econometrica, v. 52, n. 2, p. 345-362, March 1984.

FIELDS, G. S. "Labor market modelling and the urban informal sector: theory and evidence". In: TURNHAM, D.; SALOMÉ, B.; SCHWARZ, A. (Eds.). The informal sector revisited. Paris: OECD, 2000, p. 49-69.

FIRPO, S.; FORTIN, N. M.; LEMIEUX, T. Unconditional quantile regressions. Econometrica, v. 77, n. 3, p. 953-973, 2009.

FONTES, A. Ensaios sobre informalidade no Brasil. Tese (Doutorado em Economia) - Instituto de Economia, Universidade Federal do Rio de Janeiro, Rio de Janeiro, 2009.

FONTES, A.; PERO, V. L. Segmentação do mercado de trabalho e mobilidade de renda entre 2002 e 2007. In: ENCONTRO NACIONAL DE ECONOMIA, 36, Salvador, 2008. Anais... Niterói: ANPEC, 2008.

GERRY, C. Petty production and capitalism production in Dakar: the crisis of the self-employed. World Development, v. 6, n. 9/10, n. 1147-1160, 1978.

HART, K. Informal income opportunities and urban development in Ghana. The Journal of Modern African Studies, v. 2, n. 1, March 1973.

HUBER, M.; MELLY, B. A test of the conditional independence assumption in sample selection models. Journal of Applied Econometrics, v. 30, n. 7, p. 1144-1168, 2015.

ILO - INTERNATIONAL LABOUR ORGANIZATION. Employment, incomes and equality: a strategy for increasing productive employment in Kenya. Geneva: ILO, 1972.

ILO - INTERNATIONAL LABOUR ORGANIZATION. "Decent work and the informal economy: report VI”. In: INTERNATIONAL LABOUR CONFERENCE, 90, Geneva, 2002. Anais... Geneva: ILO, 2002.

JUHN, C.; MURPHY, K.M.; PIERCE, B. "Accounting for the slowdown in black-white wage convergence". In: KOSTERS, M. (Ed.). Workers and their wages. Washington, D.C: American Enterprise Institute Press, 1991, p. 107-143. 
KOENKER, R.; BASSETT, G. Jr. Regression quantiles. Econometrica, v. 46, n. 1, p. 33-50, January 1978.

LEE, L. Generalized econometric models with selectivity. Econometrica, v. 51, n. 2, p. 507-512, 1983.

MACHADO, J. A. F.; MATA, J. Counterfactual decomposition of changes in wage distributions using quantile regression. Journal of Applied Econometrics, v. 20, p. 445-465, March 2005.

MACHADO, A. F.; OLIVEIRA, A. M. H. C.; ANTIGO, M. "Evolução recente do diferencial de rendimentos entre setor formal e informal no Brasil (1999 a 2005): evidências a partir de regressões quantílicas”. In: BARROS, R. P.; FOGUEL, M.; ULYSSEA, G. (Orgs.). Desigualdade de renda no Brasil: uma análise da queda recente. Vol. 2. Brasília: IPEA, 2007, p. 447471.

MALONEY, W. F. Does informality imply segmentation in urban labor markets? Evidence from sectoral transitions in Mexico. World Bank Economic Review, v. 13, n. 2, p. 275-302, May 1999.

MELLY, B. Decomposition of differences in distribution using quantile regression. Labour Economics, v. 12, n. 4, p. 577-90, 2005.

MENEZES-FILHO, N.A.; MENDES, M.; DE ALMEIDA, S. E. O diferencial de salários formalinformal no Brasil: segmentação ou viés de seleção? Revista Brasileira de Economia, v. 58, n. 2, p. 235-248, abr./jun. 2004.

MENEZES-FILHO, N.; FERNANDES, R.; PICCHETTI, P. “Educação e queda recente da desigualdade no Brasil”. In: BARROS, R. P.; FOGUEL, M. N.; ULYSSEA, G. (Orgs.) Desigualdade de renda no Brasil: uma análise da queda recente. Vol. 2. Brasília: IPEA, 2007, p. 285304.

MOSER, C. O. N. Informal sector or petty commodity production: dualism or dependence in urban development? World Development, v. 6, n. 9/10, p. 1041-1064, 1978.

NEAL, D. The measured black-white wage gap among women is too small. Journal of Political Economy, v. 112, p. 1-28, 2004.

NEUMAN, S.; OAXACA, R. Wage decompositions with selectivity-corrected wage equations: a methodological note. The Journal of Economic Inequality, v. 2, n. 1, p. 3-10, 2004.

NICODEMO, C. Gender pay gap and quantile regression in European families. Discussion Papers, Bonn, IZA, n. 3978, 2009.

OAXACA, R. Male-Female wages differentials in urban labor markets. International Economic Review, v. 14, n. 3, p. 693-709, 1973.

OLIVETTI, C.; PETRONGOLO, B. Unequal pay or unequal employment? A cross-country analysis of gender gaps. Journal of Labor Economics, v. 26, n. 4, p. 621-654, 2008.

OSTERMAN, P. An empirical study of labor market segmentation. Industrial and Labor Relations Review, v. 28, n. 4, p. 508-523, July 1975.

PAREDES, D. The impact of the occupations and economic activities on the wage gender gap using a counterfactual framework. Working Paper, Antofagasta, UCN, n. 2012-08, April 2012. 
PICCHIO, M.; MUSSIDA, C. Gender wage gap: a semi-parametric approach with sample selection correction. Discussion Paper, Bonn, IZA, n. 4783, 2010.

PIORE, M. J. Notes for a theory of labor markets stratification. Working Paper, MIT, n. 95, 1972.

PORTES, A.; CASTELLS, M.; BENTON, L. A. The informal economy: studies in advanced and less developed countries. Baltimore: Johns Hopkins University Press, 1989.

REICH, M.; GORDON, D. M.; EDWARDS, R. C. Dual labor markets: a theory of labor market segmentation. American Economic Review, v. 63, n. 2, p. 359-365, May 1973.

SALARDI, P. "Wage disparities and occupational intensity by gender and race in Brazil: an empirical analysis using quantile decomposition techniques". In: IZA/WORLD BANK CONFERENCE: EMPLOYMENT AND DEVELOPMENT, 7, New Delhi, 4-6 November, 2012. Anais... Bonn: IZA/World Bank, 2012.

SANTOS, R. V.; RIBEIRO E. P. Diferenciais de rendimentos entre homens e mulheres no Brasil revisitado: explorando o 'teto de vidro' In: SEMINÁRIO DE PESQUISA DO IE-UFRJ, Rio de Janeiro, IE-UFRJ, 02 mai. 2006. Disponível em: <http://www.ie.ufrj.br/eventos/seminarios/pesquisa/texto06_05_02.pdf>.

SMITH, M. D. Modelling sample selection using Archimedean copulas. The Econometrics Journal, v. 6, n. 1, p. 99-123, 2003.

SOUZA, P. R.; TOKMAN, V. E. The informal urban sector in Latin America. International Labour Review, v. 114, n. 3, p. 355-365, November/December 1976.

SOUZA, P. R. Emprego, salários e pobreza. São Paulo: Hucitec; Campinas: FUNCAMP, 1980.

TANNURI-PIANTO, M. E.; PIANTO, D. Informal employment in Brazil - A choice at the top and segmentation at the bottom: a quantile regression approach. Textos para Discussão, Brasília, UnB, n. 236, ago. 2002.

TOKMAN, V. E. An exploration into the nature of informal-formal sector interrelationships. Monograph on Employment, n. 2, Lima, PREALC/OIT, April 1977.

ULYSSEA, G. "Segmentação no mercado de trabalho e desigualdade de rendimentos no Brasil: uma análise empírica”. In: BARROS, R. P.; FOGUEL, M.; ULYSSEA, G. (Orgs.). Desigualdade de renda no Brasil: uma análise da queda recente. Vol. 2. Brasília: IPEA, 2007, p. 417445.

UTHOFF, A. Subempleo, segmentación, movilidad ocupacional y distribución del ingreso del trabajo. El caso del Gran Santiago em 1969 y 1978. Estudios de Economía, v. 10, n. 1, p. 113 146, jun. 1983.

VIETORISZ, T.; HARRISON, B. Labor market segmentation: positive feedback and divergent development. American Economic Review, v. 63, n. 2, p. 366-376, May 1973. 


\section{APÊNDICE A}

Tabela A1 - Estimativas do $1^{\circ}$ estágio do modelo de Dubin e McFadden, por logit multinomial, para a seleção entre a não participação no mercado de trabalho e a participação no emprego formal ou informal, mulheres e homens ocupados de 25 a 59 anos, Brasil, 2000/2010

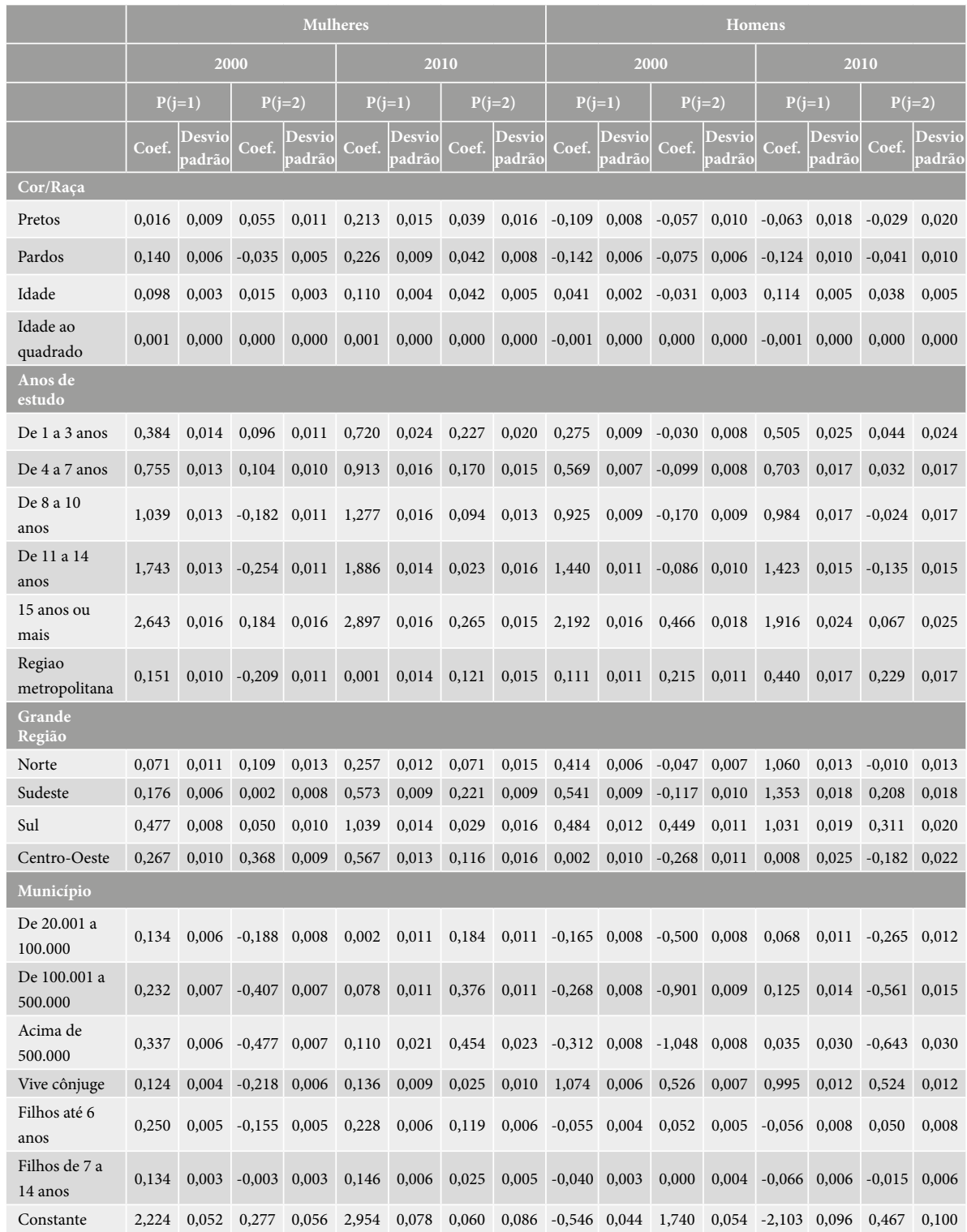

Nota: $P(j=1)$ : probabilidade de participação no emprego formal; $P(j=2)$ : probabilidade de participação no emprego informal. Categorias-base: Brancos; Menos de 1 ano de estudo; Região não-metropolitana; Região Nordeste; Municípios com até 20.000 habitantes; Não vivem com cônjuge; Não tem filhos com até 6 anos; Não tem filhos de 7 a 14 anos. (*) Todos os coeficientes são estatisticamente significativos ao nível de $1 \%$.

Fonte: Elaboração própria, a partir dos dados dos Censos 2000 e 2010. 


\section{Tabela A2 - Estimativas do $2^{\circ}$ estágio das Regressões Quantílicas para o log do rendimento/ hora, emprego formal e informal, mulheres ocupadas de 25 a 59 anos, Brasil, 2000/2010}

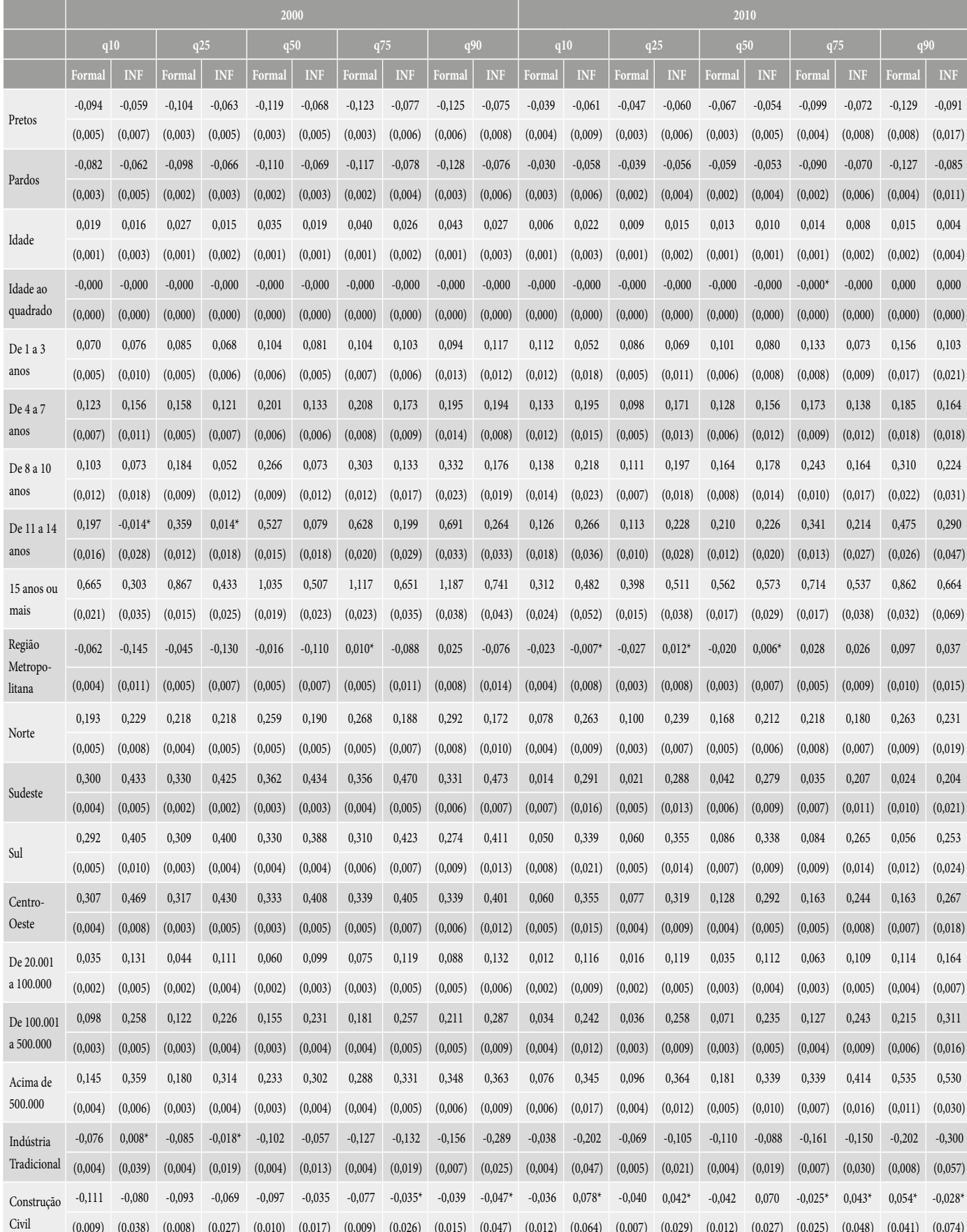


Tabela A2 - Estimativas do $2^{\circ}$ estágio das Regressões Quantílicas para o log do rendimento/hora, emprego formal e informal, mulheres ocupadas de 25 a 59 anos, Brasil, 2000/2010 (continuação)

\begin{tabular}{|c|c|c|c|c|c|c|c|c|c|c|c|c|c|c|c|c|c|c|c|c|}
\hline & \multicolumn{10}{|c|}{2000} & \multicolumn{10}{|c|}{2010} \\
\hline & \multicolumn{2}{|c|}{ q10 } & \multicolumn{2}{|c|}{$q 25$} & \multicolumn{2}{|c|}{$q 50$} & \multicolumn{2}{|c|}{$q 75$} & \multicolumn{2}{|c|}{$q 90$} & \multicolumn{2}{|c|}{$q 10$} & \multicolumn{2}{|c|}{$q 25$} & \multicolumn{2}{|c|}{$q 50$} & \multicolumn{2}{|c|}{$q 75$} & \multicolumn{2}{|c|}{$q 90$} \\
\hline & Formal & INF & Formal & INF & Formal & INF & Formal & INF & Formal & $\mathrm{INF}$ & Formal & INF & Formal & INF & Formal & INF & Formal & INF & Formal & INF \\
\hline \multirow{2}{*}{$\begin{array}{l}\text { Serviços } \\
\text { Distributivos }\end{array}$} & $-0,170$ & $-0,000^{*}$ & $-0,165$ & $-0,046$ & $-0,164$ & $-0,029$ & $-0,148$ & $0,026^{*}$ & $-0,117$ & $0,041^{*}$ & $-0,130$ & $-0,111$ & $-0,131$ & $-0,091$ & $-0,159$ & $-0,075$ & $-0,178$ & $-0,018^{*}$ & $-0,163$ & $0,025^{*}$ \\
\hline & $(0,004)$ & $(0,036)$ & $(0,004)$ & $(0,020)$ & $(0,005)$ & $(0,013)$ & $(0,005)$ & $(0,018)$ & $(0,007)$ & $(0,026)$ & $(0,004)$ & $(0,044)$ & $(0,005)$ & $(0,024)$ & $(0,004)$ & $(0,021)$ & $(0,006)$ & $(0,029)$ & $(0,008)$ & $(0,061)$ \\
\hline \multirow{2}{*}{$\begin{array}{l}\text { Serviços } \\
\text { Produtivos }\end{array}$} & $-0,043$ & 0,087 & $-0,044$ & 0,049 & $-0,015$ & 0,075 & 0,076 & 0,103 & 0,158 & $0,053^{*}$ & $-0,048$ & 0,115 & $-0,063$ & 0,058 & $-0,069$ & 0,072 & $-0,021$ & 0,088 & 0,061 & $0,107^{\star}$ \\
\hline & $(0,005)$ & $(0,038)$ & $(0,005)$ & $(0,024)$ & $(0,005)$ & $(0,016)$ & $(0,005)$ & $(0,020)$ & $(0,008)$ & $(0,032)$ & $(0,004)$ & $(0,045)$ & $(0,005)$ & $(0,021)$ & $(0,005)$ & $(0,022)$ & $(0,006)$ & $(0,033)$ & $(0,009)$ & $(0,060)$ \\
\hline \multirow{2}{*}{$\begin{array}{l}\text { Serviços } \\
\text { Sociais }\end{array}$} & $-0,035$ & 0,227 & $-0,035$ & 0,186 & $-0,042$ & 0,174 & $-0,048$ & 0,137 & $-0,061$ & $-0,006^{*}$ & $-0,005^{*}$ & 0,325 & $-0,021$ & 0,268 & $-0,054$ & 0,244 & $-0,070$ & 0,208 & $-0,081$ & $0,064^{*}$ \\
\hline & $(0,005)$ & $(0,035)$ & $(0,005)$ & $(0,020)$ & $(0,004)$ & $(0,013)$ & $(0,003)$ & $(0,017)$ & $(0,006)$ & $(0,024)$ & $(0,003)$ & $(0,043)$ & $(0,004)$ & $(0,020)$ & $(0,004)$ & $(0,017)$ & $(0,007)$ & $(0,026)$ & $(0,008)$ & $(0,057)$ \\
\hline \multirow{2}{*}{$\begin{array}{l}\text { Serviços } \\
\text { Pessoais }\end{array}$} & $-0,219$ & $-0,106$ & $-0,210$ & $-0,125$ & $-0,201$ & $-0,111$ & $-0,190$ & $-0,080$ & $-0,171$ & $-0,119$ & $-0,172$ & $-0,377$ & $-0,158$ & $-0,279$ & $-0,186$ & $-0,173$ & $-0,223$ & $-0,143$ & $-0,222$ & $-0,198$ \\
\hline & $(0,006)$ & $(0,037)$ & $(0,005)$ & $(0,021)$ & $(0,005)$ & $(0,014)$ & $(0,004)$ & $(0,020)$ & $(0,009)$ & $(0,027)$ & $(0,005)$ & $(0,044)$ & $(0,004)$ & $(0,023)$ & $(0,004)$ & $(0,018)$ & $(0,007)$ & $(0,030)$ & $(0,011)$ & $(0,059)$ \\
\hline \multirow{2}{*}{ Médio } & $-0,295$ & $-0,274$ & $-0,306$ & $-0,323$ & $-0,315$ & $-0,370$ & $-0,348$ & $-0,405$ & $-0,394$ & $-0,434$ & $-0,220$ & $-0,172$ & $-0,317$ & $-0,233$ & $-0,323$ & $-0,309$ & $-0,310$ & $-0,284$ & $-0,300$ & $-0,326$ \\
\hline & $(0,004)$ & $(0,009)$ & $(0,004)$ & $(0,010)$ & $(0,003)$ & $(0,009)$ & $(0,002)$ & $(0,011)$ & $(0,004)$ & $(0,015)$ & $(0,004)$ & $(0,007)$ & $(0,002)$ & $(0,006)$ & $(0,002)$ & $(0,006)$ & $(0,002)$ & $(0,009)$ & $(0,004)$ & $(0,010)$ \\
\hline \multirow{2}{*}{ Manual } & $-0,555$ & $-0,531$ & $-0,635$ & $-0,596$ & $-0,716$ & $-0,699$ & $-0,781$ & $-0,775$ & $-0,827$ & $-0,813$ & $-0,310$ & $-0,322$ & $-0,453$ & $-0,374$ & $-0,589$ & $-0,480$ & $-0,673$ & $-0,581$ & $-0,709$ & $-0,587$ \\
\hline & $(0,006)$ & $(0,009)$ & $(0,005)$ & $(0,010)$ & $(0,003)$ & $(0,008)$ & $(0,004)$ & $(0,008)$ & $(0,006)$ & $(0,015)$ & $(0,004)$ & $(0,011)$ & $(0,003)$ & $(0,008)$ & $(0,002)$ & $(0,008)$ & $(0,004)$ & $(0,010)$ & $(0,006)$ & $(0,019)$ \\
\hline \multirow{2}{*}{ Doméstico } & $-0,618$ & $-0,430$ & $-0,730$ & $-0,581$ & $-0,807$ & $-0,754$ & $-0,859$ & $-0,876$ & $-0,920$ & $-0,954$ & $-0,315$ & $-0,140$ & $-0,445$ & $-0,286$ & $-0,592$ & $-0,459$ & $-0,689$ & $-0,577$ & $-0,714$ & $-0,647$ \\
\hline & $(0,006)$ & $(0,011)$ & $(0,005)$ & $(0,013)$ & $(0,004)$ & $(0,010)$ & $(0,006)$ & $(0,010)$ & $(0,008)$ & $(0,018)$ & $(0,006)$ & $(0,013)$ & $(0,003)$ & $(0,010)$ & $(0,003)$ & $(0,009)$ & $(0,006)$ & $(0,011)$ & $(0,010)$ & $(0,022)$ \\
\hline \multirow{2}{*}{ _ml } & $-0,116$ & 0,048 & $-0,130$ & 0,010 & $-0,137$ & $-0,038$ & $-0,139$ & $-0,065$ & $-0,137$ & $-0,087$ & $-0,072$ & 0,166 & $-0,113$ & 0,159 & $-0,127$ & 0,110 & $-0,159$ & 0,036 & $-0,197$ & $-0,013$ \\
\hline & $(0,004)$ & $(0,006)$ & $(0,004)$ & $(0,004)$ & $(0,003)$ & $(0,004)$ & $(0,004)$ & $(0,006)$ & $(0,006)$ & $(0,008)$ & $(0,005)$ & $(0,010)$ & $(0,002)$ & $(0,007)$ & $(0,003)$ & $(0,006)$ & $(0,005)$ & $(0,008)$ & $(0,008)$ & $(0,015)$ \\
\hline \multirow{2}{*}{$-\mathrm{m} 2$} & $-0,193$ & $-0,189$ & $-0,170$ & $-0,186$ & $-0,147$ & $-0,219$ & $-0,141$ & $-0,229$ & $-0,128$ & $-0,249$ & $-0,104$ & 0,052 & $-0,131$ & 0,068 & $-0,130$ & 0,065 & $-0,131$ & $-0,003$ & $-0,120$ & $-0,027$ \\
\hline & $(0,005)$ & $(0,010)$ & $(0,004)$ & $(0,007)$ & $(0,005)$ & $(0,007)$ & $(0,006)$ & $(0,010)$ & $(0,010)$ & $(0,017)$ & $(0,005)$ & $(0,012)$ & $(0,004)$ & $(0,009)$ & $(0,004)$ & $(0,005)$ & $(0,005)$ & $(0,007)$ & $(0,005)$ & $(0,016)$ \\
\hline \multirow{2}{*}{ Constante } & $-0,922$ & $-1,077$ & $-0,876$ & $-0,672$ & $-0,768$ & $-0,585$ & $-0,566$ & $-0,518$ & $-0,268$ & $-0,224$ & 0,271 & 0,102 & 0,300 & 0,724 & 0,383 & 1,134 & 0,465 & 1,212 & 0,594 & 1,495 \\
\hline & $(0,035)$ & $(0,079)$ & $(0,029)$ & $(0,053)$ & $(0,022)$ & $(0,043)$ & $(0,030)$ & $(0,059)$ & $(0,046)$ & $(0,090)$ & $(0,033)$ & $(0,112)$ & $(0,014)$ & $(0,056)$ & $(0,024)$ & $(0,050)$ & $(0,036)$ & $(0,075)$ & $(0,065)$ & $(0,130)$ \\
\hline
\end{tabular}

Nota: $\left(^{*}\right)$ Coeficientes não significativos a 5\%. Erros-padrão entre parênteses. INF=Informal.Categorias-base: Brancos; Menos de 1 ano de estudo; Região não-metropolitana; Região Nordeste; Municípios com até 20.000 habitantes; Indústria Moderna; Categoria de ocupação "Superior". Fonte: Elaboração própria, a partir dos dados dos Censos 2000 e 2010. 


\section{Tabela A3 - Estimativas do $2^{\circ}$ estágio das Regressões Quantílicas para o log do rendimento/ hora, emprego formal e informal, homens ocupados de 25 a 59 anos, Brasil, 2000/2010}

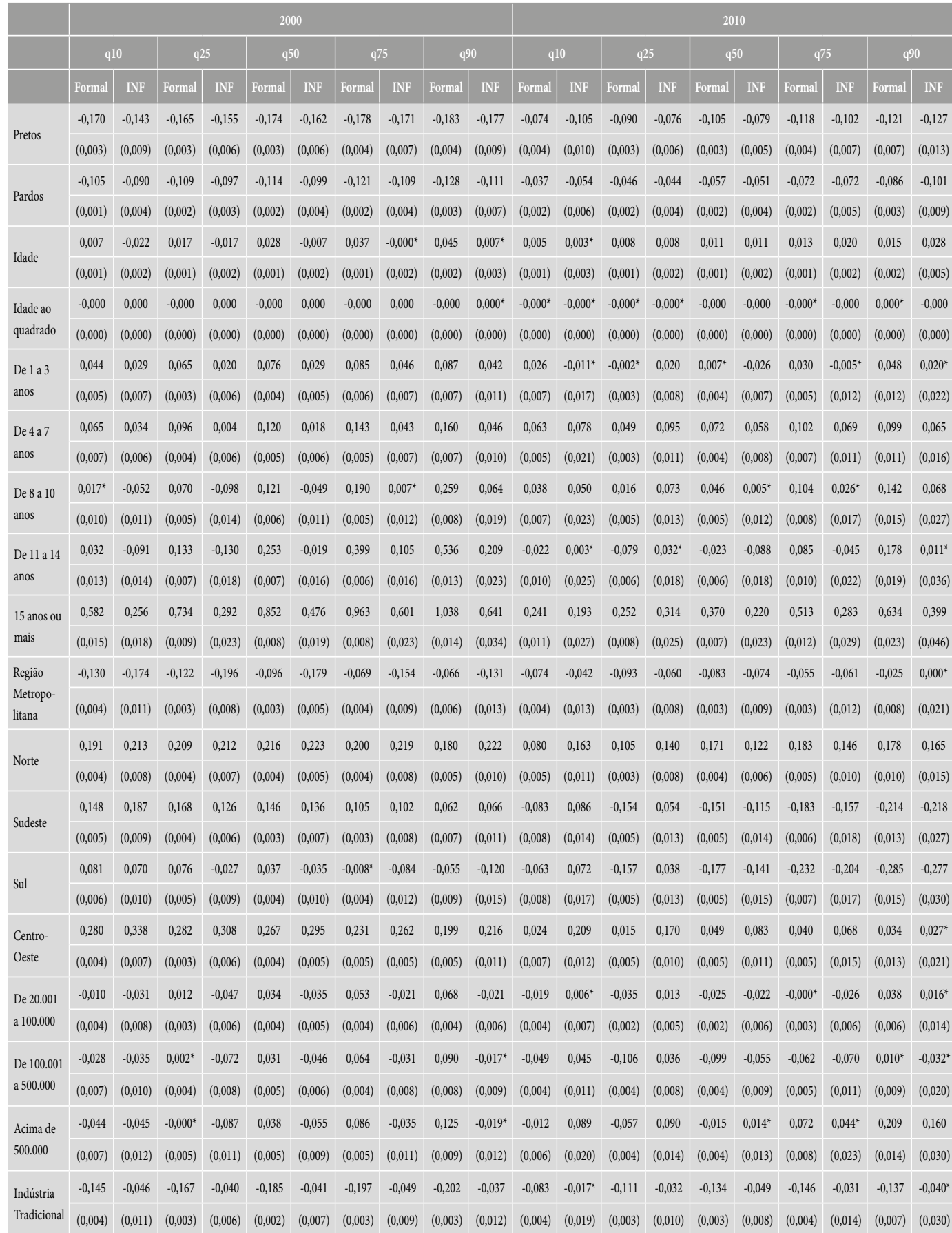




\section{Tabela A3 - Estimativas do $2^{\circ}$ estágio das Regressões Quantílicas para o log do rendimento/hora, emprego formal e informal, homens ocupados de 25 a 59 anos, Brasil, 2000/2010 (continuação)}

\begin{tabular}{|c|c|c|c|c|c|c|c|c|c|c|c|c|c|c|c|c|c|c|c|c|}
\hline & \multicolumn{10}{|c|}{2000} & \multicolumn{10}{|c|}{2010} \\
\hline & \multicolumn{2}{|c|}{$q 10$} & \multicolumn{2}{|c|}{$\mathrm{q} 25$} & \multicolumn{2}{|c|}{$q 50$} & \multicolumn{2}{|c|}{$\mathrm{q} 75$} & \multicolumn{2}{|c|}{$q 90$} & \multicolumn{2}{|c|}{$q 10$} & \multicolumn{2}{|c|}{$q 25$} & \multicolumn{2}{|c|}{$q 50$} & \multicolumn{2}{|c|}{$q 75$} & \multicolumn{2}{|c|}{$q 90$} \\
\hline \multirow{2}{*}{$\begin{array}{l}\text { Construção } \\
\text { Civil }\end{array}$} & $-0,159$ & $-0,080$ & $-0,162$ & $-0,037$ & $-0,166$ & $-0,030$ & $-0,183$ & $-0,043$ & $-0,204$ & $-0,096$ & $-0,087$ & $-0,090$ & $-0,106$ & $-0,057$ & $-0,121$ & $-0,051$ & $-0,143$ & $-0,054$ & $-0,128$ & $-0,128$ \\
\hline & $(0,003)$ & $(0,010)$ & $(0,003)$ & $(0,006)$ & $(0,004)$ & $(0,004)$ & $(0,003)$ & $(0,005)$ & $(0,005)$ & $(0,008)$ & $(0,004)$ & $(0,013)$ & $(0,004)$ & $(0,010)$ & $(0,004)$ & $(0,009)$ & $(0,003)$ & $(0,010)$ & $(0,008)$ & $(0,023)$ \\
\hline \multirow{2}{*}{$\begin{array}{l}\text { Serviços } \\
\text { Distribu- } \\
\text { tivos }\end{array}$} & $-0,191$ & $-0,124$ & $-0,192$ & $-0,094$ & $-0,181$ & $-0,059$ & $-0,166$ & $-0,015$ & $-0,157$ & 0,052 & $-0,179$ & $-0,105$ & $-0,189$ & $-0,097$ & $-0,194$ & $-0,064$ & $-0,193$ & $0,001^{*}$ & $-0,159$ & 0,065 \\
\hline & $(0,003)$ & $(0,008)$ & $(0,003)$ & $(0,006)$ & $(0,002)$ & $(0,006)$ & $(0,003)$ & $(0,006)$ & $(0,004)$ & $(0,009)$ & $(0,003)$ & $(0,017)$ & $(0,002)$ & $(0,011)$ & $(0,003)$ & $(0,008)$ & $(0,003)$ & $(0,011)$ & $(0,006)$ & $(0,026)$ \\
\hline \multirow{2}{*}{$\begin{array}{l}\text { Serviços } \\
\text { Produtivos }\end{array}$} & $-0,111$ & $-0,107$ & $-0,115$ & $-0,105$ & $-0,104$ & $-0,109$ & $-0,085$ & $-0,093$ & $-0,057$ & $-0,077$ & $-0,084$ & $0,009^{*}$ & $-0,097$ & $-0,006^{*}$ & $-0,101$ & $-0,000^{*}$ & $-0,094$ & 0,040 & $-0,043$ & 0,097 \\
\hline & $(0,005)$ & $(0,010)$ & $(0,004)$ & $(0,008)$ & $(0,003)$ & $(0,009)$ & $(0,004)$ & $(0,010)$ & $(0,004)$ & $(0,013)$ & $(0,004)$ & $(0,020)$ & $(0,004)$ & $(0,013)$ & $(0,005)$ & $(0,010)$ & $(0,005)$ & $(0,015)$ & $(0,006)$ & $(0,030)$ \\
\hline $\begin{array}{l}\text { Serviços } \\
\text { Sociais }\end{array}$ & $(0,004)$ & $(0,009)$ & $(0,004)$ & $(0,006)$ & $(0,004)$ & $(0,006)$ & $(0,003)$ & $(0,009)$ & $(0,005)$ & $(0,015)$ & $(0,005)$ & $(0,016)$ & $(0,003)$ & $(0,014)$ & $(0,004)$ & $(0,009)$ & $(0,004)$ & $(0,012)$ & $(0,007)$ & $(0,027)$ \\
\hline \multirow{2}{*}{$\begin{array}{l}\text { Serviços } \\
\text { Pessoais }\end{array}$} & $-0,360$ & $-0,276$ & $-0,352$ & $-0,228$ & $-0,334$ & $-0,190$ & $-0,312$ & $-0,137$ & $-0,275$ & $-0,049$ & $-0,248$ & $-0,235$ & $-0,269$ & $-0,189$ & $-0,303$ & $-0,168$ & $-0,318$ & $-0,131$ & $-0,292$ & $-0,088$ \\
\hline & $(0,006)$ & $(0,010)$ & $(0,005)$ & $(0,009)$ & $(0,005)$ & $(0,009)$ & $(0,005)$ & $(0,009)$ & $(0,007)$ & $(0,020)$ & $(0,004)$ & $(0,021)$ & $(0,004)$ & $(0,012)$ & $(0,004)$ & $(0,010)$ & $(0,006)$ & $(0,017)$ & $(0,011)$ & $(0,026)$ \\
\hline \multirow{2}{*}{ Médic } & $-0,277$ & $-0,228$ & $-0,305$ & $-0,260$ & $-0,352$ & $-0,286$ & $-0,381$ & $-0,340$ & $-0,424$ & $-0,369$ & $-0,202$ & $-0,142$ & $-0,272$ & $-0,189$ & $-0,308$ & $-0,231$ & $-0,342$ & $-0,252$ & $-0,387$ & $-0,263$ \\
\hline & $(0,004)$ & $(0,013)$ & $(0,004)$ & $(0,007)$ & $(0,004)$ & $(0,008)$ & $(0,004)$ & $(0,013)$ & $(0,005)$ & $(0,017)$ & $(0,004)$ & $(0,011)$ & $(0,003)$ & $(0,009)$ & $(0,004)$ & $(0,009)$ & $(0,004)$ & $(0,011)$ & $(0,008)$ & $(0,021)$ \\
\hline \multirow{2}{*}{ Manu } & $-0,488$ & $-0,472$ & $-0,543$ & $-0,542$ & $-0,628$ & $-0,614$ & $-0,693$ & $-0,707$ & $-0,743$ & $-0,801$ & $-0,322$ & $-0,302$ & $-0,424$ & $-0,348$ & $-0,531$ & $-0,447$ & $-0,634$ & $-0,544$ & $-0,707$ & $-0,547$ \\
\hline & $(0,004)$ & $(0,014)$ & $(0,004)$ & $(0,008)$ & $(0,003)$ & $(0,008)$ & $(0,004)$ & $(0,013)$ & $(0,004)$ & $(0,015)$ & $(0,004)$ & $(0,010)$ & $(0,003)$ & $(0,008)$ & $(0,004)$ & $(0,008)$ & $(0,004)$ & $(0,009)$ & $(0,008)$ & $(0,015)$ \\
\hline \multirow{2}{*}{ Doméstico } & $-0,602$ & $-0,496$ & $-0,673$ & $-0,623$ & $-0,781$ & $-0,757$ & $-0,862$ & $-0,929$ & $-0,928$ & $-1,105$ & $-0,404$ & $-0,384$ & $-0,493$ & $-0,401$ & $-0,598$ & $-0,493$ & $-0,707$ & $-0,618$ & $-0,704$ & $-0,697$ \\
\hline & $(0,011)$ & $(0,018)$ & $(0,010)$ & $(0,008)$ & $(0,008)$ & $(0,010)$ & $(0,009)$ & $(0,013)$ & $(0,012)$ & $(0,028)$ & $(0,018)$ & $(0,026)$ & $(0,011)$ & $(0,014)$ & $(0,011)$ & $(0,014)$ & $(0,016)$ & $(0,017)$ & $(0,037)$ & $(0,029)$ \\
\hline _m & $(0,004)$ & $(0,007)$ & $(0,004)$ & $(0,004)$ & $(0,003)$ & $(0,005)$ & $(0,002)$ & $(0,006)$ & $(0,005)$ & $(0,008)$ & $(0,005)$ & $(0,012)$ & $(0,003)$ & $(0,009)$ & $(0,004)$ & $(0,006)$ & $(0,007)$ & $(0,007)$ & $(0,012)$ & $(0,014)$ \\
\hline \multirow{2}{*}{ _m2 } & $-0,291$ & $-0,280$ & $-0,251$ & $-0,349$ & $-0,226$ & $-0,315$ & $-0,187$ & $-0,307$ & $-0,148$ & $-0,279$ & $-0,204$ & $-0,073$ & $-0,277$ & $-0,087$ & $-0,269$ & $-0,241$ & $-0,240$ & $-0,262$ & $-0,196$ & $-0,249$ \\
\hline & $(0,008)$ & $(0,011)$ & $(0,006)$ & $(0,011)$ & $(0,005)$ & $(0,009)$ & $(0,005)$ & $(0,013)$ & $(0,010)$ & $(0,015)$ & $(0,005)$ & $(0,010)$ & $(0,003)$ & $(0,010)$ & $(0,004)$ & $(0,011)$ & $(0,005)$ & $(0,011)$ & $(0,010)$ & $(0,015)$ \\
\hline \multirow{2}{*}{ Constante } & $-0,250$ & 0,206 & 0,018 & 0,298 & 0,264 & 0,631 & 0,579 & 0,974 & 0,912 & 1,426 & 0,220 & 0,676 & 0,247 & 0,743 & 0,565 & 0,508 & 1,020 & 0,677 & 1,519 & 1,005 \\
\hline & $(0,030)$ & $(0,046)$ & $(0,020)$ & $(0,039)$ & $(0,016)$ & $(0,042)$ & $(0,018)$ & $(0,052)$ & $(0,046)$ & $(0,055)$ & $(0,030)$ & $(0,078)$ & $(0,016)$ & $(0,054)$ & $(0,029)$ & $(0,037)$ & $(0,034)$ & $(0,051)$ & $(0,074)$ & $(0,122)$ \\
\hline
\end{tabular}

Nota: (*) Coeficientes não significativos a 5\%. Erros-padrão entre parênteses. INF=Informal.Categorias-base: Brancos; Menos de 1 ano de estudo; Região não-metropolitana; Região Nordeste; Municípios com até 20.000 habitantes; Indústria Moderna; Categoria de ocupação "Superior". Fonte: Elaboração própria, a partir dos dados dos Censos 2000 e 2010. 
Tabela A4 - Decomposição de Machado e Mata para o diferencial de rendimentos entre emprego formal e informal, mulheres e homens ocupados de 25 a 59 anos, Brasil, 2000/2010

\begin{tabular}{|c|c|c|c|c|c|c|c|c|c|c|c|c|c|c|c|c|}
\hline \multirow{3}{*}{ Quantil } & \multicolumn{8}{|c|}{ Mulheres } & \multicolumn{8}{|c|}{ Homens } \\
\hline & \multicolumn{2}{|c|}{$\begin{array}{c}\text { Diferencia } \\
\text { IBruto }\end{array}$} & \multicolumn{2}{|c|}{$\begin{array}{c}\text { Diferencial } \\
\text { Predito }\end{array}$} & \multicolumn{2}{|c|}{ Características } & \multicolumn{2}{|c|}{ Coeficientes } & \multicolumn{2}{|c|}{$\begin{array}{c}\text { Diferencial } \\
\text { Bruto }\end{array}$} & \multicolumn{2}{|c|}{$\begin{array}{c}\text { Diferencial } \\
\text { Predito }\end{array}$} & \multicolumn{2}{|c|}{ Características } & \multicolumn{2}{|c|}{ Coeficientes } \\
\hline & 2000 & 2010 & 2000 & 2010 & 2000 & 2010 & 2000 & 2010 & 2000 & 2010 & 2000 & 2010 & 2000 & 2010 & 2000 & 2010 \\
\hline \multirow{2}{*}{$5 \%$} & 0,741 & 1,114 & 0,693 & 1,049 & 0,269 & 0,170 & 0,424 & 0,879 & 0,552 & 0,754 & 0,553 & 0,773 & 0,248 & 0,142 & 0,305 & 0,632 \\
\hline & & & $(0,026)$ & $(0,026)$ & $(0,018)$ & $(0,015)$ & $(0,024)$ & $(0,027)$ & & & $(0,029)$ & $(0,028)$ & $(0,024)$ & $(0,014)$ & $(0,027)$ & $(0,031)$ \\
\hline \multirow{2}{*}{$10 \%$} & 0,635 & 0,841 & 0,614 & 0,825 & 0,297 & 0,132 & 0,316 & 0,692 & 0,525 & 0,588 & 0,515 & 0,579 & 0,263 & 0,151 & 0,253 & 0,428 \\
\hline & & & $(0,022)$ & $(0,023)$ & $(0,015)$ & $(0,009)$ & $(0,019)$ & $(0,023)$ & & & $(0,022)$ & $(0,022)$ & $(0,021)$ & $(0,011)$ & $(0,021)$ & $(0,024)$ \\
\hline \multirow{2}{*}{$15 \%$} & 0,531 & 0,693 & 0,587 & 0,688 & 0,326 & 0,139 & 0,261 & 0,549 & 0,504 & 0,425 & 0,498 & 0,487 & 0,269 & 0,167 & 0,229 & 0,320 \\
\hline & & & $(0,02)$ & $(0,021)$ & $(0,016)$ & $(0,008)$ & $(0,016)$ & $(0,020)$ & & & $(0,022)$ & $(0,019)$ & $(0,020)$ & $(0,011)$ & $(0,021)$ & $(0,020)$ \\
\hline $20 \%$ & 0,588 & 0,531 & 0,576 & 0,593 & 0,353 & 0,152 & 0,224 & 0,440 & 0,536 & 0,348 & 0,491 & 0,440 & 0,275 & 0,185 & 0,216 & 0,255 \\
\hline \multirow{2}{*}{$25 \%$} & 0,542 & 0,425 & 0,576 & 0,524 & 0,379 & 0,172 & 0,197 & 0,352 & 0,55 & 0,386 & 0,487 & 0,416 & 0,280 & 0,199 & 0,207 & 0,217 \\
\hline & & & $(0,018)$ & $(0,019)$ & $(0,018)$ & $(0,008)$ & $(0,014)$ & $(0,017)$ & & & $(0,018)$ & $(0,015)$ & $(0,018)$ & $(0,013)$ & $(0,019)$ & $(0,015)$ \\
\hline \multirow{2}{*}{$30 \%$} & 0,588 & 0,354 & 0,584 & 0,476 & 0,406 & 0,195 & 0,178 & 0,282 & 0,541 & 0,383 & 0,482 & 0,405 & 0,285 & 0,211 & 0,197 & 0,194 \\
\hline & & & $(0,019)$ & $(0,017)$ & $(0,018)$ & $(0,010)$ & $(0,014)$ & $(0,015)$ & & & $(0,019)$ & $(0,014)$ & $(0,018)$ & $(0,013)$ & $(0,019)$ & $(0,014)$ \\
\hline \multirow{2}{*}{$35 \%$} & 0,578 & 0,345 & 0,597 & 0,449 & 0,434 & 0,223 & 0,163 & 0,226 & 0,47 & 0,355 & 0,48 & 0,401 & 0,291 & 0,221 & 0,189 & 0,180 \\
\hline & & & $(0,019)$ & $(0,017)$ & $(0,018)$ & $(0,011)$ & $(0,014)$ & $(0,015)$ & & & $(0,019)$ & $(0,013)$ & $(0,018)$ & $(0,013)$ & $(0,019)$ & $(0,013)$ \\
\hline \multirow{2}{*}{$40 \%$} & 0,658 & 0,363 & 0,614 & 0,434 & 0,463 & 0,254 & 0,151 & 0,180 & 0,506 & 0,45 & 0,477 & 0,402 & 0,299 & 0,230 & 0,179 & 0,171 \\
\hline & & & $(0,019)$ & $(0,016)$ & $(0,019)$ & $(0,013)$ & $(0,015)$ & $(0,014)$ & & & $(0,018)$ & $(0,015)$ & $(0,016)$ & $(0,014)$ & $(0,018)$ & $(0,013)$ \\
\hline \multirow{2}{*}{$45 \%$} & 0,632 & 0,336 & 0,634 & 0,434 & 0,497 & 0,289 & 0,137 & 0,144 & 0,511 & 0,444 & 0,478 & 0,403 & 0,307 & 0,239 & 0,171 & 0,164 \\
\hline & & & $(0,02)$ & $(0,016)$ & $(0,019)$ & $(0,014)$ & $(0,015)$ & $(0,013)$ & & & $(0,018)$ & $(0,015)$ & $(0,017)$ & $(0,014)$ & $(0,018)$ & $(0,013)$ \\
\hline $50 \%$ & & & $(0,019)$ & $(0,017)$ & $(0,020)$ & $(0,015)$ & $(0,015)$ & $(0,014)$ & & & $(0,019)$ & $(0,016)$ & $(0,018)$ & $(0,015)$ & $(0,018)$ & $(0,014)$ \\
\hline & 0,687 & 0,466 & 0,679 & 0,457 & 0,570 & 0,363 & 0,109 & 0,094 & 0,492 & 0,405 & 0,482 & 0,407 & 0,328 & 0,256 & 0,154 & 0,151 \\
\hline $55 \%$ & & & $(0,019)$ & $(0,018)$ & $(0,021)$ & $(0,016)$ & $(0,017)$ & $(0,015)$ & & & $(0,018)$ & $(0,018)$ & $(0,018)$ & $(0,017)$ & $(0,018)$ & $(0,014)$ \\
\hline & 0,681 & 0,511 & 0,704 & 0,473 & 0,611 & 0,399 & 0,093 & 0,074 & 0,511 & 0,405 & 0,488 & 0,410 & 0,342 & 0,265 & 0,146 & 0,145 \\
\hline $00 \%$ & & & $(0,02)$ & $(0,019)$ & $(0,021)$ & $(0,017)$ & $(0,017)$ & $(0,016)$ & & & $(0,021)$ & $(0,019)$ & $(0,020)$ & $(0,019)$ & $(0,018)$ & $(0,015)$ \\
\hline $65 \%$ & 0,726 & 0,47 & 0,731 & 0,488 & 0,653 & 0,432 & 0,079 & 0,055 & 0,523 & 0,431 & 0,497 & 0,413 & 0,358 & 0,276 & 0,139 & 0,137 \\
\hline $05 \%$ & & & $(0,022)$ & $(0,023)$ & $(0,022)$ & $(0,021)$ & $(0,019)$ & $(0,018)$ & & & $(0,021)$ & $(0,019)$ & $(0,020)$ & $(0,018)$ & $(0,018)$ & $(0,016)$ \\
\hline $70 \%$ & 0,706 & 0,524 & 0,756 & 0,502 & 0,694 & 0,462 & 0,062 & 0,040 & 0,539 & 0,432 & 0,510 & 0,418 & 0,377 & 0,289 & 0,133 & 0,129 \\
\hline & & & $(0,023)$ & $(0,024)$ & $(0,023)$ & $(0,022)$ & $(0,020)$ & $(0,019)$ & & & $(0,023)$ & $(0,021)$ & $(0,022)$ & $(0,020)$ & $(0,020)$ & $(0,018)$ \\
\hline & 0,784 & 0,588 & 0,776 & 0,510 & 0,731 & 0,484 & 0,045 & 0,026 & 0,565 & 0,492 & 0,527 & 0,421 & 0,405 & 0,303 & 0,122 & 0,118 \\
\hline & & & $(0,024)$ & $(0,026)$ & $(0,025)$ & $(0,024)$ & $(0,023)$ & $(0,019)$ & & & $(0,026)$ & $(0,024)$ & $(0,022)$ & $(0,022)$ & $(0,021)$ & $(0,021)$ \\
\hline $80 \%$ & 0,788 & 0,588 & 0,787 & 0,511 & 0,757 & 0,496 & 0,030 & 0,015 & 0,629 & 0,511 & 0,550 & 0,424 & 0,436 & 0,318 & 0,114 & 0,106 \\
\hline 0070 & & & $(0,026)$ & $(0,028)$ & $(0,026)$ & $(0,026)$ & $(0,026)$ & $(0,022)$ & & & $(0,029)$ & $(0,029)$ & $(0,025)$ & $(0,025)$ & $(0,024)$ & $(0,025)$ \\
\hline 8 & 0,799 & 0,606 & 0,793 & 0,501 & 0,771 & 0,488 & 0,022 & 0,013 & 0,588 & 0,511 & 0,576 & 0,423 & 0,471 & 0,332 & 0,105 & 0,091 \\
\hline & & & $(0,027)$ & $(0,031)$ & $(0,028)$ & $(0,029)$ & $(0,030)$ & $(0,028)$ & & & $(0,035)$ & $(0,032)$ & $(0,031)$ & $(0,030)$ & $(0,028)$ & $(0,029)$ \\
\hline & 0,82 & 0,608 & 0,778 & 0,477 & 0,761 & 0,454 & 0,017 & 0,023 & 0,6 & 0,511 & 0,596 & 0,410 & 0,510 & 0,338 & 0,085 & 0,072 \\
\hline $90 \%$ & & & $(0,031)$ & $(0,033)$ & $(0,031)$ & $(0,033)$ & $(0,035)$ & $(0,031)$ & & & $(0,039)$ & $(0,039)$ & $(0,039)$ & $(0,038)$ & $(0,037)$ & $(0,039)$ \\
\hline $95 \%$ & 0,693 & 0,511 & 0,725 & 0,429 & 0,703 & 0,389 & 0,022 & 0,040 & 0,591 & 0,466 & 0,592 & 0,373 & 0,532 & 0,339 & 0,060 & 0,034 \\
\hline & & & $(0,042)$ & $(0,044)$ & $(0,038)$ & $(0,036)$ & $(0,044)$ & $(0,044)$ & & & $(0,053)$ & $(0,048)$ & $(0,045)$ & $(0,044)$ & $(0,055)$ & $(0,051)$ \\
\hline
\end{tabular}

Fonte: Elaboração própria, a partir dos dados dos Censos 2000 e 2010. 